\title{
Article
}

\section{Upregulation of Cathepsin X in Glioblastoma: Interplay with $\gamma$-Enolase and the Effects of Selective Cathepsin X Inhibitors}

\author{
Bernarda Majc ${ }^{1,2}{ }^{(D}$, Anamarija Habič ${ }^{1,2}{ }^{\text {, Metka Novak }}{ }^{1}$, Ana Rotter ${ }^{1}{ }^{\mathbb{D}}$, Andrej Porčnik ${ }^{3}$, Jernej Mlakar ${ }^{4}$, \\ Vera Župunski ${ }^{5} \mathbb{D}^{D}$, Urša Pečar Fonović ${ }^{6}$, Damijan Knez ${ }^{6}{ }^{\mathbb{D}}$, Nace Zidar ${ }^{6}{ }^{\mathbb{D}}$, Stanislav Gobec ${ }^{6} \mathbb{D}^{\mathbb{D}}$, Janko Kos ${ }^{6}$, \\ Tamara Lah Turnšek ${ }^{1,5}$, Anja Pišlar ${ }^{6, *}$ a and Barbara Breznik 1,*(D)
}

Citation: Majc, B.; Habič, A.; Novak, M.; Rotter, A.; Porčnik, A.; Mlakar, J.; Župunski, V.; Fonović, U.P.; Knez, D.; Zidar, N.; et al. Upregulation of Cathepsin X in Glioblastoma: Interplay with $\gamma$-Enolase and the Effects of Selective Cathepsin X Inhibitors. Int. J. Mol. Sci. 2022, 23, 1784. https://doi.org/10.3390/ ijms23031784

Academic Editors: Thomas Dittmar, Janko Kos and Jörg W. Bartsch

Received: 7 January 2022

Accepted: 1 February 2022

Published: 4 February 2022

Publisher's Note: MDPI stays neutral with regard to jurisdictional claims in published maps and institutional affiliations.

Copyright: (c) 2022 by the authors Licensee MDPI, Basel, Switzerland. This article is an open access article distributed under the terms and conditions of the Creative Commons Attribution (CC BY) license (https:// creativecommons.org/licenses/by/ $4.0 /)$
1 Department of Genetic Toxicology and Cancer Biology, National Institute of Biology, 111 Večna pot, 1000 Ljubljana, Slovenia; bernarda.majc@nib.si (B.M.); anamarija.habic@nib.si (A.H.); metka.novak@nib.si (M.N.); ana.rotter@nib.si (A.R.); tamara.lah@nib.si (T.L.T.)

2 Jozef Stefan International Postgraduate School, 39 Jamova cesta, 1000 Ljubljana, Slovenia

3 Department of Neurosurgery, University Medical Centre Ljubljana, 7 Zaloška cesta, 1000 Ljubljana, Slovenia; andrej.porcnik@kclj.si

4 Institute of Pathology, Faculty of Medicine, University of Ljubljana, 2 Korytkova ulica, 1000 Ljubljana Slovenia; jernej.mlakar@mf.uni-lj.si

5 Chair of Biochemistry, Faculty of Chemistry and Chemical Technology, University of Ljubljana, 113 Večna pot, 1000 Ljubljana, Slovenia; vera.zupunski@fkkt.uni-lj.si

6 Faculty of Pharmacy, University of Ljubljana, 7 Aškerčeva cesta, 1000 Ljubljana, Slovenia; ursa.pecarfonovic@ffa.uni-lj.si (U.P.F.); damijan.Knez@ffa.uni-lj.si (D.K.); nace.zidar@ffa.uni-lj.si (N.Z.); stanislav.gobec@ffa.uni-lj.si (S.G.); janko.kos@ffa.uni-lj.si (J.K.)

* Correspondence: barbara.breznik@nib.si (B.B.); anja.pislar@ffa.uni-lj.si (A.P.), Tel.: +386-(0)59-232-870 (B.B.); +386-(0)14-169-526 (A.P.)

Abstract: Glioblastoma (GBM) is the most common and deadly primary brain tumor in adults. Understanding GBM pathobiology and discovering novel therapeutic targets are critical to finding efficient treatments. Upregulation of the lysosomal cysteine carboxypeptidase cathepsin $X$ has been linked to immune dysfunction and neurodegenerative diseases, but its role in cancer and particularly in GBM progression in patients is unknown. In this study, cathepsin $X$ expression and activity were found to be upregulated in human GBM tissues compared to low-grade gliomas and nontumor brain tissues. Cathepsin X was localized in GBM cells as well as in tumor-associated macrophages and microglia. Subsequently, potent irreversible (AMS36) and reversible (Z7) selective cathepsin $X$ inhibitors were tested in vitro. Selective cathepsin $X$ inhibitors decreased the viability of patientderived GBM cells as well as macrophages and microglia that were cultured in conditioned media of GBM cells. We next examined the expression pattern of neuron-specific enzyme $\gamma$-enolase, which is the target of cathepsin $X$. We found that there was a correlation between high proteolytic activity of cathepsin $X$ and $C$-terminal cleavage of $\gamma$-enolase and that cathepsin $X$ and $\gamma$-enolase were colocalized in GBM tissues, preferentially in GBM-associated macrophages and microglia. Taken together, our results on patient-derived material suggest that cathepsin $\mathrm{X}$ is involved in GBM progression and is a potential target for therapeutic approaches against GBM.

Keywords: glioblastoma; cathepsin X; $\gamma$-enolase; tumor microenvironment; glioblastoma stem cells; cathepsin $\mathrm{X}$ inhibitors

\section{Introduction}

Glioblastoma (GBM) remains the most lethal and common primary brain tumor in adults despite standard treatment including maximal safe surgical removal, chemotherapy, and radiotherapy [1,2]. GBM is classified by the World Health Organization as grade IV glioma and responds poorly to therapy, with a 5-year patient survival rate of less than $5 \%$ [3-6]. Therefore, there is an urgent need to identify new therapeutic targets to develop efficient antitumor approaches. 
Inter- and intratumoral heterogeneity [7], presence of therapy-resistant GBM stem cells (GSCs) [8,9], rapid tumor invasion [10], and a supportive tumor microenvironment (TME) [11,12] are responsible for therapy resistance [7,9,11,13-15]. GBMs are classified according to The Cancer Genome Atlas (TCGA) into three molecular subtypes based on genomic profiling: proneural (PN), classical (CL), and mesenchymal (MES) GBMs that differ in prognosis and are associated with a unique molecular fingerprint [16,17]. Intratumoral heterogeneity exists at both the genetic and cellular levels. GBM cells co-opt components of the TME to create a complex milieu that promotes tumor development, invasion, and resistance to treatment [12]. Myeloid cells, consisting primarily of two distinct cell types, macrophages and microglia, are greatly affected by the TME [18] and represent the major component of the GBM TME and can account for up to 30-40\% of the total tumor mass $[19,20]$ where tumor-associated macrophages (TAMs) are predominant $[21,22]$. These cells within the tumor mass play a crucial role in enhancing tumor growth and dissemination via suppression of inflammation, promotion of angiogenesis, and extracellular matrix remodeling [18].

Cathepsins belong to the C1A papain superfamily of cysteine peptidases, which comprises 11 members, including cathepsins B, L, K, S, and X. Most of the cathepsins are endopeptidases that catalyze the cleavage of peptide bonds within polypeptide chains, whereas some of them are carboxy exopeptidases, such as cathepsins B and X, and amino exopeptidases, such as cathepsins $\mathrm{C}$ and $\mathrm{H}$, that cleave their substrates at the $\mathrm{C}$ - or N-terminus, respectively [23]. Cathepsins are involved in the regulation of numerous physiological processes and are mostly, but not exclusively, found in endosomes and lysosomes for protein degradation [24] in nonneoplastic human cells. In pathological conditions such as inflammation and cancer, cathepsins may be present in the nucleus, excessively secreted into the cytoplasm and extracellularly, where they can be associated with the plasma membrane of cancer cells [25]. Besides cancer cells, many other noncancerous cell types in the TME express cathepsins, including fibroblasts, neutrophils, mast cells, T cells, endothelial cells, and TAMs, playing specific roles in cancer and antitumor immune response [26]. In tumors, the expression of lysosomal cysteine cathepsins is often elevated and is generally associated with poor patient prognosis [26]. Cathepsins have been shown to exert tumor-promoting functions [27], such as promoting tumor growth, invasion [28], and resistance to therapy [26,29], although some of them also contribute to tumor suppression [30-33].

Not much is known about the expression and function of cathepsin X in GBM. Recently, we have shown that cathepsin $X$ is abundantly expressed in GBM tumors and localizes in perivascular GSC niches, but its role is still unknown [34]. Cathepsin X (also known as cathepsin $\mathrm{Z}$ or cathepsin P) is a cysteine carboxypeptidase that is predominantly localized in cells of the immune system such as macrophages, monocytes, and dendritic cells [23], indicating its role in immune cell maturation, proliferation, migration, adhesion, and signal transduction $[35,36]$. There is increasing evidence that higher levels of cathepsin $X$ are associated with various types of cancer [23] and are presumably involved in the mechanisms of tumor progression that lead to alterations in cellular processes, including cell proliferation and invasion. In addition, cathepsin $X$ has been detected in the brain in glial cells, neurons, oligodendrocytes, and ependymal cells [23,35,37-40]. Cathepsin X is involved in inflammation-induced neurodegeneration $[39,41]$. The neurodegenerative action of cathepsin $X$ involves the sequential cleavage of the $C$-terminal amino acids of $\gamma$-enolase, abolishing neurotrophic activity of $\gamma$-enolase [42]. It is also known as neuron-specific enolase and is an enzyme of the glycolytic pathway expressed predominantly in neurons and cells of the neuroendocrine system. The enzyme occurs as two isozymes, $\gamma \gamma$ and $\alpha \gamma$. The $\gamma \gamma$ isoform is mainly found in mature neurons, whereas the $\alpha \gamma$ isoenzyme is localized in nonneuronal cells such as microglia, oligodendrocytes, and astrocytes [43]. Cytoplasmic $\gamma$-enolase is involved in enhanced aerobic glycolysis associated with cell proliferation. The additional active site at the $C$-terminal part of the molecule, which is not part of the catalytic element involved in glycolysis, is thought to support the growth, survival, and differentiation of both developing and mature neurons [44,45]. In cancer cells, $\gamma$-enolase is considered to act as a pro-survival 
factor [46]. These pro-survival and neuritogenic activities mediated by $\gamma$-enolase are regulated by the cysteine peptidase cathepsin X. However, in brain cancer pathology, the underlying mechanism of $\gamma$-enolase action and its regulation by cathepsin $\mathrm{X}$ remain unclear.

In the present study, we aimed to investigate the abundance and possible role of cathepsin X in GBM, focusing on the regulation of $\gamma$-enolase. Specifically, we investigated the localization as well as the expression level and activity of cathepsin $X$ in tumor tissues from GBM patients. To explore the therapeutic potential of targeting cathepsin $X$, we tested the effects of its selective irreversible and reversible cathepsin $X$ inhibitors on the viability of patient-derived GBM cells, as well as macrophages and microglia treated with conditioned GBM cell media. To investigate the interplay of cathepsin $X$ and $\gamma$-enolase in GBM, colocalization studies were performed with specific antibodies for cathepsin $\mathrm{X}$ and $\gamma$-enolase in GBM tissue sections. In addition, to reveal the relevance of cathepsin $\mathrm{X}$ activity with respect to proteolytic processing of $\gamma$-enolase in GBM tissues, the protein levels of the total and the intact active form of $\gamma$-enolase were determined in GBM tissue lysates, and the effect of the peptide mimicking the intact $C$-terminal end of $\gamma$-enolase on GBM cell, macrophage, and microglia proliferation was assessed.

\section{Results}

\subsection{Expression and Enzymatic Activity of Cathepsin X Are Upregulated in GBM Tissues}

Expression of the cathepsin $X$ gene was evaluated in low-grade gliomas (LGG), GBMs, and nontumor brain tissues as well as in primary GBM cells and GSCs established from GBM tissues. The highest relative mRNA expression of cathepsin $X$ was measured in recurrent GBM, followed by de novo GBM and LGG tissues. The relative mRNA expression of cathepsin $X$ was significantly lower in nontumor brain tissues compared to recurrent and de novo GBM tissues (Figure 1A). Cathepsin $\mathrm{X}$ was expressed in GBM cells and normal astrocytes and was higher than in GSCs (Figure 1B). Moreover, we analyzed mRNA levels of cathepsin X in the four GBM subtypes, MES, PN, CL, and mixed (MIX). This classification is based on the expression values of 12 subtype-specific genes according to Behnan et al. [47], to which we added three more genes based on in-house gene expression analyses [48]. The PN subtype was classified by the expression levels of OLIG2, P2RX7, STMN4, SOX10, NOTCH, and ERBB3 genes. The CL subtype was classified by the expression levels of NF-KB, ACSBG1, S100A4, and KCNF1, the MES subtype - by the expression levels of DAB2, TGFB1, THBS1, COL1A2, and COL1A1. The cathepsin X gene was expressed in all GBM subtypes, but the lowest level was detected in the MIX subtype. Statistical significance was observed only for the relative mRNA expression of cathepsin X between the CL and MIX subtypes (Figure 1C). Cathepsin X median mRNA levels in our study of $48 \mathrm{GBM}$ patients did not correlate with the overall survival of GBM patients (Figure S1). To confirm the differences at the protein level of cathepsin $X$ and its enzymatic activity, proteins were isolated from the dissected GBM and nontumor brain tissues. ELISA revealed no significant difference in cathepsin $X$ expression between the groups; however, we observed a trend towards increased protein level of cathepsin $X$ in GBM (Figure 1D). On the other hand, significantly higher enzymatic activity of cathepsin $X$ (Figure 1E) was detected in GBM tissues as compared to nontumor brain tissues.

\subsection{Macrophage-Specific and Microglia-Specific Localization of Cathepsin X in GBM Tissues}

High levels of the cathepsin X protein were detected in all the tested GBM tissue sections. Next, we analyzed which cells express cathepsin X. As cathepsin X is predominantly expressed in immune-like cells, we used CD68 and Iba1 as biomarkers of immune cells present in GBM tissues, namely macrophages and microglia, respectively. GFAP was used as an astrocytic marker, SOX2 and CD133 - as biomarkers for GBM progenitor cells GSCs. Cellular localization of cathepsin $\mathrm{X}$ in GBM was determined by immunofluorescence staining in tissue sections from four GBM patients (Figure 2 and Figure S2) and in nontumor brain tissue sections (Figure S2). Figure 2 and Figure S2 show that cathepsin X mostly localized within cells of the innate immune system, macrophages, and microglia (markers CD68, Iba1) and was also 
expressed in some GFAP-, SOX2-, and CD133-positive cells. Cathepsin X also colocalized with microglia biomarker Iba1 in nontumor brain tissues (Figure S2).

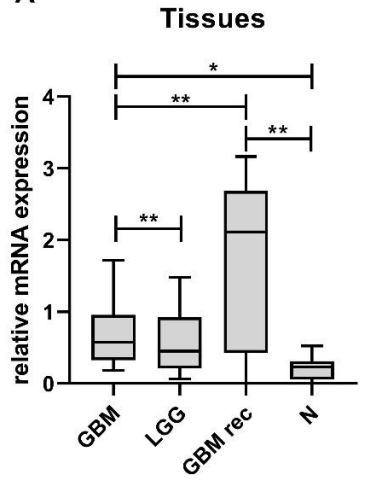

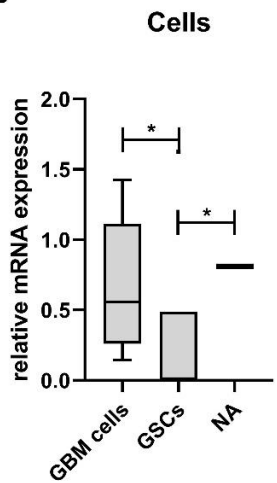

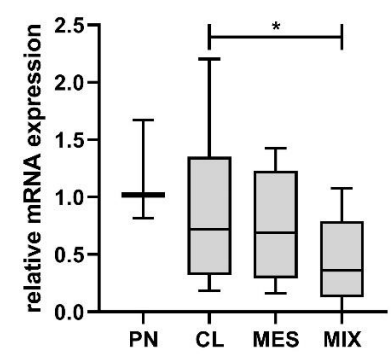

D

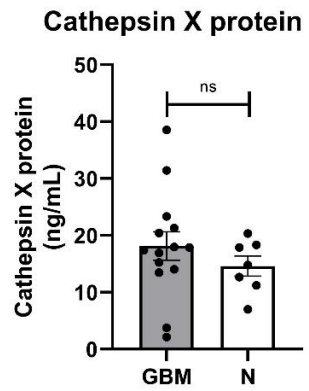

E

Cathepsin X activity

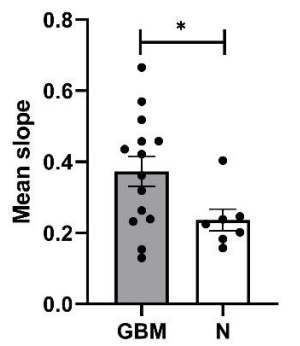

Figure 1. Cathepsin $X$ mRNA levels, protein expression, and enzymatic activity in GBM. (A) Relative mRNA level of cathepsin $X$ was increased in de novo GBM tissues $(n=43)$ and recurrent GBM (GBM rec, $n=5)$ compared to LGG $(n=14)$ and nontumor brain tissues $(\mathrm{N}, n=16)$. (B) Cathepsin $\mathrm{X}$ at the mRNA level was expressed in primary GBM cells $(n=17)$ and normal astrocytes (NA, $n=1)$ and at a low level in GSCs $(n=6)$. (C) Cathepsin X mRNA was expressed in classical (CL, $n=18)$, proneural (PN, $n=3$ ), mesenchymal (MES, $n=17$ ), and mixed (MIX, $n=25$ ) GBM subtypes. The boxplots show relative cathepsin $\mathrm{X}$ mRNA expression in different sample groups. Different $Y$-axis scales are presented. (D) The cathepsin X protein level was not different in GBM tissues $(n=14)$ compared to the nontumor tissue control $(\mathrm{N}, n=7)$. (E) The cathepsin $\mathrm{X}$ enzyme activity was significantly increased in GBM tissues $(n=14)$ compared to the nontumor tissue control $(\mathrm{N}, \mathrm{n}=7)$. The data are presented as the mean values \pm SEM. ${ }^{*} p<0.05,{ }^{* *} p<0.01$.

\subsection{Cathepsin X Inhibition Decreases Viability of Primary Patient-Derived GBM Cells and GBM-Associated Cells}

First, GBM cell viability and proliferation were examined after $48 \mathrm{~h}$ of treatment with two selective inhibitors of cathepsin X, irreversible inhibitor AMS36 and reversible inhibitor Z7. The effect of inhibitors was tested on both primary patient-derived GBM cells NIB140 and GSCs NCH421k. These cells showed differential expression of GBM stem cell and differentiation markers (Figure S3). Primary patient-derived GBM cells NIB140 expressed low levels of stem cell markers and high levels of differentiation markers GFAP and TUB33. In contrast, GSCs NCH421k expressed higher levels of GSC markers PROM1, SOX2, OLIG2, NOTCH1, OCT4, and CD15 and lower levels of differentiation markers than NIB140(Figure S3). AMS36 decreased the viability of NIB140 cells up to $45 \%$, of Z7 cells-up to $20 \%$ as compared to the vehicle control (0.25\% DMSO) (Figure 3A). Similarly, AMS36 and Z7 reduced proliferation of NIB140 cells as shown by the CFSE staining assay. An increase in the CFSE fluorescence intensity of cells means a decrease in cell proliferation in the cell culture. CFSE-labeled NIB140 cells showed an increased mean of CFSE fluorescence intensity of $5 \%$ in the presence of AMS36 and Z7 compared to the control (Figure S4A). Proliferation of NCH421k cells was not altered after treatment with cathepsin $X$ inhibitors (Figure S4B). We then tested the effect of cathepsin 
X inhibitors AMS36 and Z7 on macrophages and microglia that were exposed to soluble factors secreted by GBM cells and GSCs. We performed coculture models where we collected media from GBM cells NIB140 and GSCs NCH421k cells and transferred the conditioned media to PMA-differentiated THP-1 cells (macrophages) and BV-2 cells (microglia) in the presence of increasing concentrations of cathepsin X inhibitors. AMS36 inhibited cell viability of macrophages THP-1 treated with the NIB140/NCH421k-conditioned medium at the highest concentrations tested (Figure 3B). A stronger effect of AMS36 and Z7 on cell viability was observed in microglial BV-2 cells treated with NIB140 and NCH421k conditioned media. AMS36 decreased viability by up to $60 \%$ at the highest concentrations (5-20 $\mu \mathrm{M})$, whereas Z7 also showed an effect at lower concentrations in both BV-2 cells (Figure 3C). To test the effects of cathepsin $X$ inhibitors on GBM cell invasion, a 3D cell invasion assay was performed. All the tested inhibitors inhibited invasion of NIB140 cells by up to $20 \%$. Z7 inhibitor impaired invasion of NCH421k cells by up to $20 \%$ (Figure S5A).
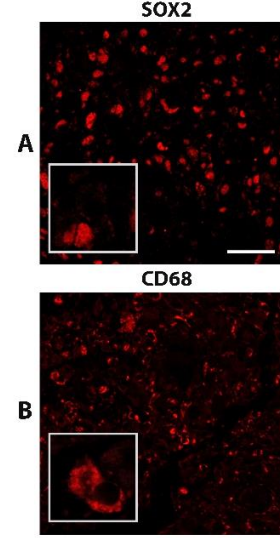

GFAP

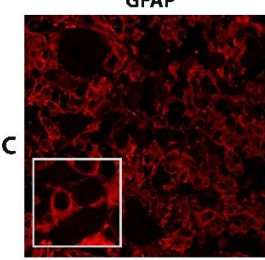

CD133

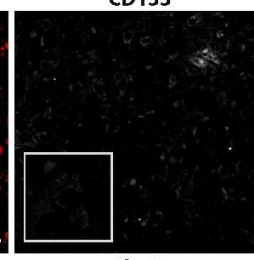

lba1

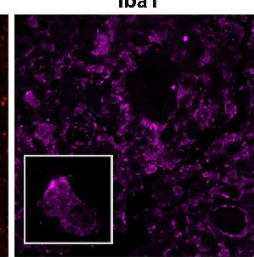

sox2

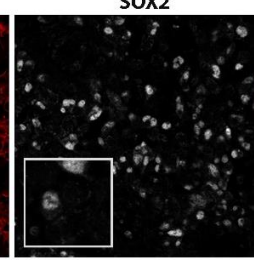

Cathepsin $\mathrm{X}$

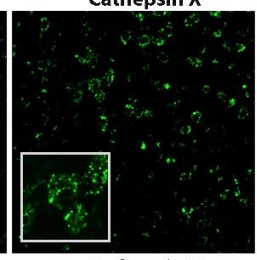

Cathepsin X

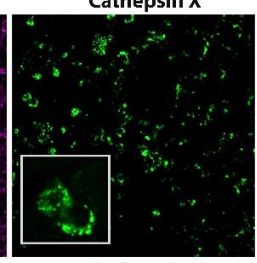

Cathepsin X

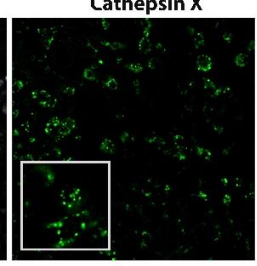

Merged

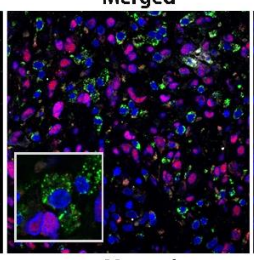

Merged
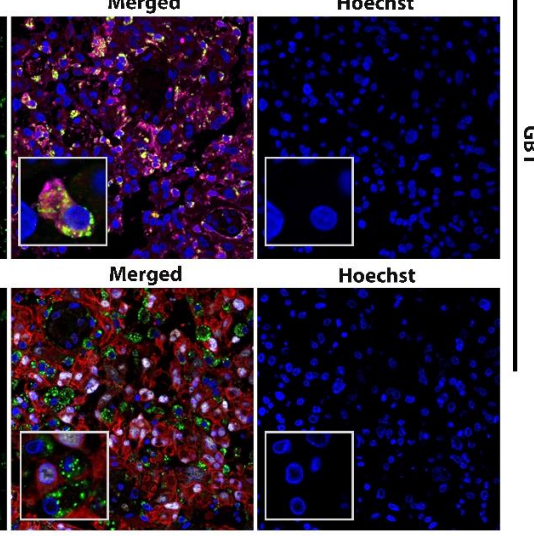

Figure 2. Localization of cathepsin $\mathrm{X}$ in CD68-positive and Iba-1-positive cells. Representative images of triple immunofluorescence staining of cathepsin X (green) and markers of (A) GSCs (SOX2-red, CD133-grey), (B) macrophages and microglia (CD68-red) and microglia (Iba1—purple), and (C) GBM cells and astrocytes (GFAP-red) and GSCs (SOX2-grey) are shown. The nuclei were counterstained with Hoechst 33258 (Hoechst, blue). Scale bar $=50 \mu \mathrm{m}$.

\subsection{Interplay of Cathepsin $X$ and $\gamma$-Enolase in GBM Tissues}

Neuron-specific enolase, or $\gamma$-enolase, is aberrantly expressed in GBMs [49,50], and it is one of the molecular targets of cathepsin X, which cleaves the C-terminal amino acids L433 and V432 of $\gamma$-enolase (Figure 4A-1) [42]. To gain insight into the role of cathepsin X in GBM, we explored the possible interaction of cathepsin $X$ and its target $\gamma$-enolase in GBM tissues. To test whether both proteins colocalize, we used three different primary antibodies against $\gamma$-enolase: a $\gamma$-enolase (D-7) antibody specific for the epitope between amino acids 41-73 near the N-terminus, a $\gamma$-enolase (NSE-P2) antibody against the internal region (amino acids 271-285) to detect total $\gamma$-enolase, and a $\gamma$-enolase (NSE-P1) antibody against amino acids 416-433 in the C-terminal region to detect intact active $\gamma$-enolase (Figure 4A,B). In Figure 4B-1 and Figure 4B-3, partial or no colocalization of cathepsin $\mathrm{X}$ and $\gamma$-enolase was observed when using an antibody recognizing the $\mathrm{N}$-terminal (Figure 4B-1) or C-terminal end of $\gamma$-enolase (Figure 4B-3). However, in Figure 4B-2 and Figure S6, noticeable colocalization of cathepsin $X$ and $\gamma$-enolase was observed when the primary antibodies against the internal region of $\gamma$-enolase were used. Because of different colocalization patterns, we next determined the 
protein levels of the intact active form, which is the C-terminally noncleaved form of $\gamma$-enolase, and the total form of $\gamma$-enolase in GBM tissues. The protein levels measured by means of "inhouse" ELISA were significantly lower for the intact active form of $\gamma$-enolase in GBM tissues as compared to total $\gamma$-enolase (both the intact active form and cleaved $\gamma$-enolase). Additionally, the protein level of noncleaved $\gamma$-enolase was significantly lower in GBM tissues as compared to the nontumor brain tissues (Figure $4 \mathrm{C}$ ). Results of immunofluorescence staining and ELISA suggested that upregulated cathepsin $\mathrm{X}$ activity in GBM tissues may regulate the protein level of the intact active end of $\gamma$-enolase in GBM by cleaving the C-terminus of $\gamma$-enolase (Figure $1 \mathrm{E}$ and Figure 4B,C). In order to further explore the type of cells where the colocalization of cathepsin $\mathrm{X}$ and $\gamma$-enolase is present, we conducted triple immunofluorescence staining to detect colocalization in immune-like cells in GBM tissues. The analysis revealed that cathepsin $X$ and $\gamma$-enolase colocalized in CD68-positive cells (Figures 5 and S7).

A

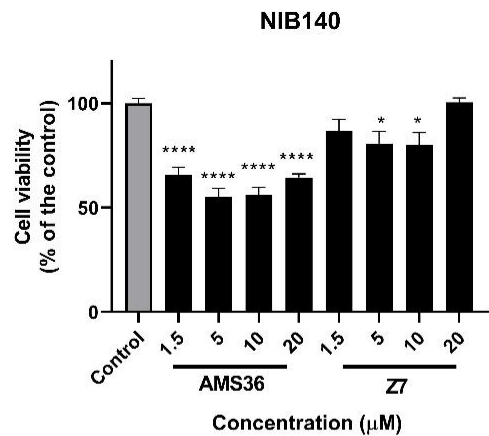

B

THP-1 (macrophages)/NIB140

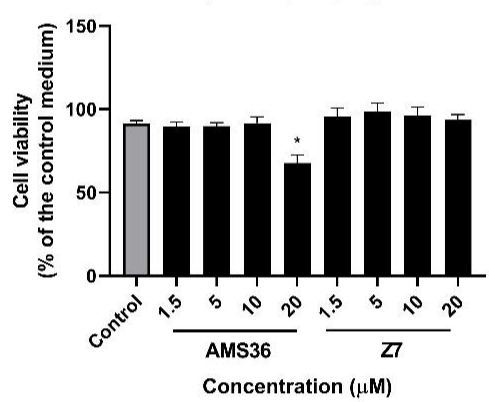

THP-1 (macrophages)/NCH421k

C

BV-2 (microglia)/NIB140

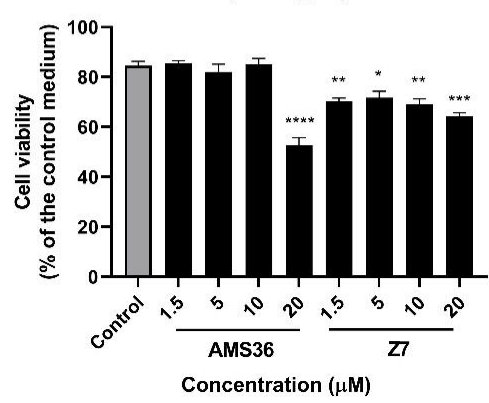

BV-2 (microglia)/NCH421k

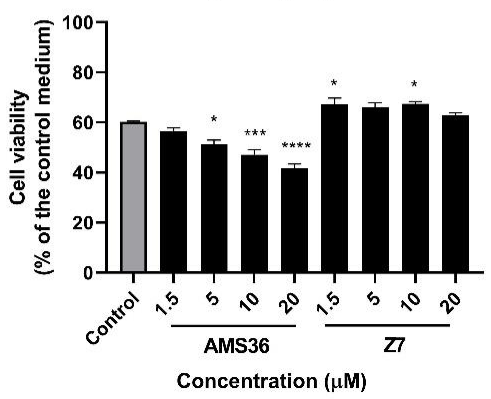

Figure 3. Effects of cathepsin X inhibitors AMS36 and Z7 on viability of GBM cells and GBMassociated cells. GBM cells NIB140 (A), differentiated macrophage THP-1 cells (B), and BV-2 microglial cells (C) exposed to the NIB140- and NCH421k-conditioned media were treated with cathep$\sin \mathrm{X}$ inhibitors AMS36 and Z7 at various concentrations. Cell viability was then assessed using the MTS assay. The control means a DMSO solvent (0.25\%). The control medium was a blank GBM cell/GSC medium without soluble molecules secreted from GBM cells/GSCs. The data are presented as the mean values \pm SEM. ${ }^{*} p<0.05,{ }^{* *} p<0.01,{ }^{* * *} p<0.001$, and ${ }^{* * * *} p<0.0001$. 


\subsection{Proliferation of GBM Cells, GSCs, and GBM-Associated Cells Affected by the $\gamma$-Enolase Peptide}

As we observed significantly reduced levels of the intact active form of $\gamma$-enolase in GBM tissues and as the peptide mimicking the intact $C$-terminal end of $\gamma$-enolase promotes proliferation of neuronal cells $[44,53]$, we were interested whether intact active $\gamma$-enolase has a functional role for proliferation of cancer cells, macrophages, and microglia. The cells were treated with a range of concentrations of the $\gamma$-enolase peptide ( $\gamma$-Eno), which mimics the $C$-terminal end of $\gamma$-enolase, for $48 \mathrm{~h}$, and cell proliferation was evaluated afterwards using CFSE staining. First, proliferation of both GBM cells NIB140 and GSCs NCH421k increased after treatment with the $\gamma$-Eno peptide (Figure 6A). The CFSE-stained NIB140 cells showed an up to $8 \%$ decrease in the mean fluorescence intensity, and NCH421k cells 7\% decrease following $\gamma$-Eno treatment. Second, $\gamma$-Eno peptide increased the proliferation of microglial BV-2 cells grown in the NCH421kconditioned media by up to $15 \%$, but did not affect the proliferation of differentiated THP1 macrophages grown in the NIB140/NCH421k cell-conditioned media (Figure 6B,C). Treatment with the highest concentration of $\gamma$-Eno decreased invasion of NIB140 and $\mathrm{NCH} 421 \mathrm{k}$ cells by $15 \%$ and $25 \%$, respectively (Figure S5B).
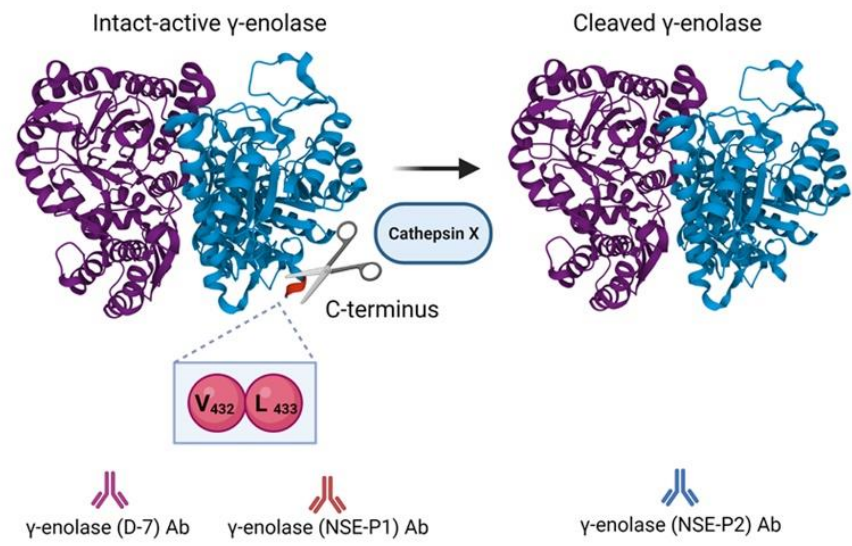

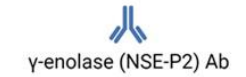

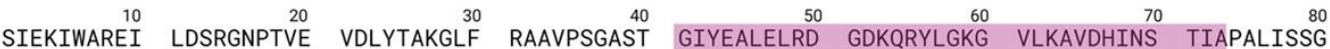
LSVVEQEKLD NLMLELDGTE NKSKFGANAI LGVSLAVCKA GAAERELPLY RHIAQLAGNS DLILPVPAFN VINGGSHAGN

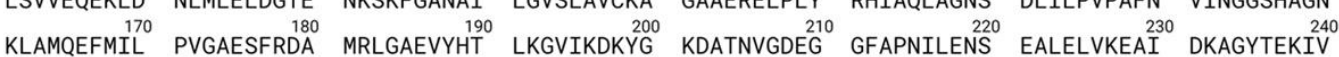

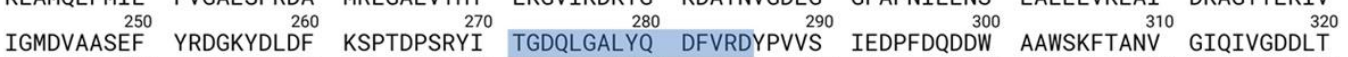

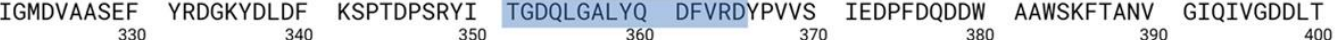
VTNPKRIERA VEEKACNCLL LKVNQIGSVT EAIQACKLAQ ENGWGVMVSH RSG 330 RSTEDTFI ADLVVGLCTG QIKTGAPCRS ERLAKYNQLM $\stackrel{410}{2}$ RIEEELGDEA RFAGHNFRNP $\stackrel{430}{\text { SVL }}$

B

$$
\text { Cathepsin } x \text { o }
$$

B-1

Hoechst CatX $\gamma$-enolase (D-7)

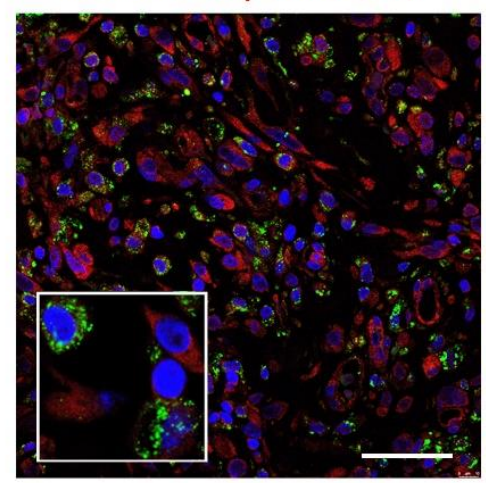

B-3

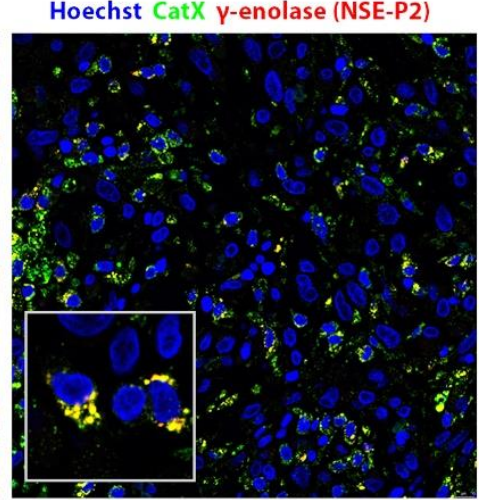

Hoechst CatX $\gamma$-enolase (NSE-P1)

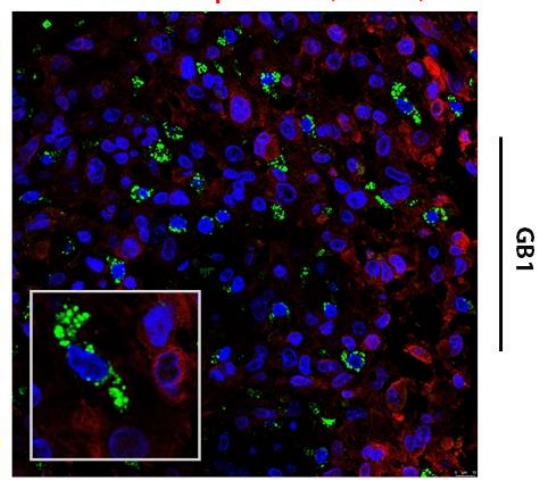




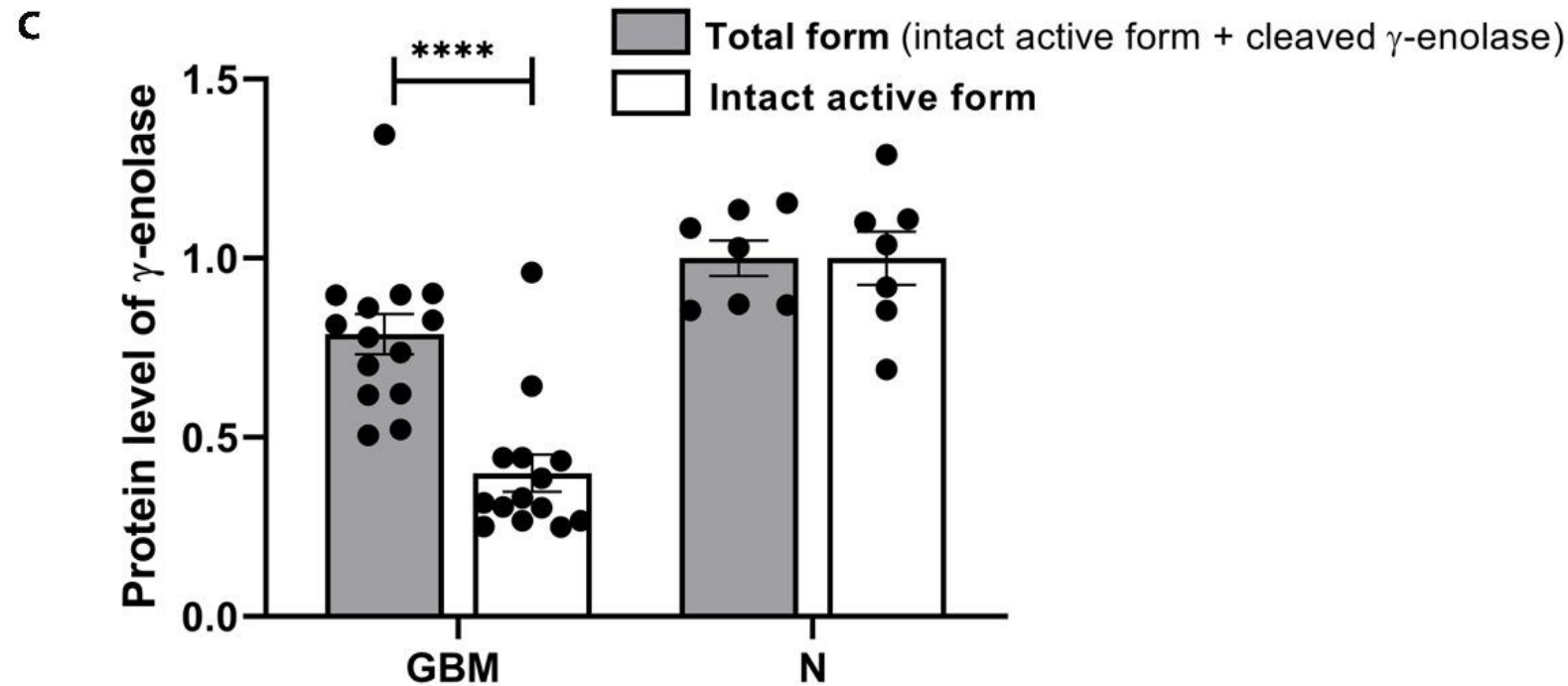

Figure 4. Colocalization of cathepsin $X$ and $\gamma$-enolase in GBM tissues. (A) A structure of the $\gamma$-enolase dimer and cleavage of $\mathrm{C}$-terminal amino acids by cathepsin $\mathrm{X}(\mathrm{A}-1)$. Three different primary antibodies against $\gamma$-enolase were used: A $\gamma$-enolase (D-7) antibody specific for the epitope between amino acids 41-73 near the N-terminus (purple amino acid sequence), a $\gamma$-enolase (NSE-P2) antibody against the internal region (amino acids 271-285, blue amino acid sequence), and a $\gamma$-enolase (NSE-P1) antibody against amino acids 416-433 in the C-terminal region (red amino acid sequence) (A-2). Total $\gamma$-enolase was detected using the NSE-P2 antibody, whereas the intact active form was detected using the NSE-P1 antibody. (B) Double immunofluorescence staining for cathepsin $\mathrm{X}$ and $\gamma$-enolase. In Figure B-1 and Figure B-3, no or partial colocalization of cathepsin $X$ and $\gamma$-enolase was observed. In Figure B-2, colocalization of both proteins was observed, suggesting that cathepsin $X$ colocalizes mainly with cleaved $\gamma$-enolase. The cell nuclei were counterstained with Hoechst 33258 (Hoechst, blue). Scale bar $=50 \mu \mathrm{m}$. (C) Significantly lower levels of the intact active form of $\gamma$-enolase were observed in GBM tissues compared to the nontumor brain tissue control (N). Protein levels of both forms of $\gamma$-enolase in GBM and nontumor brain tissues were obtained by means of ELISA. The bars represent the means with individual values ( $n=14$ of GBM and $n=7$ of nontumor tissue samples) \pm SEM. ${ }^{* * *} p<0.0001$. Image A-1 was created with Mol*Viewer [51] based on RCSB PDB (rcsb.org) ID 1TE6 [52] and image A was created with BioRender.com.
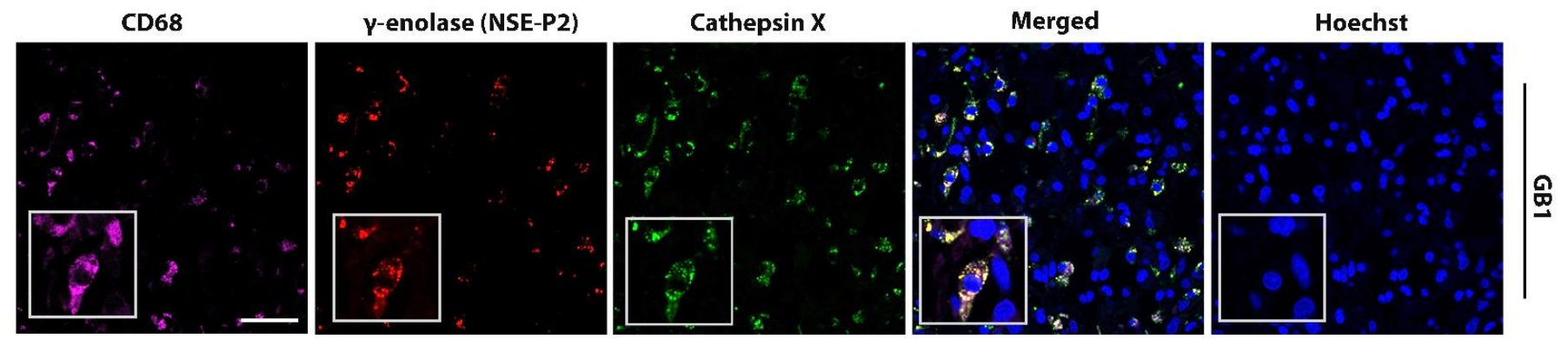

Figure 5. Colocalization of cathepsin $\mathrm{X}$ and $\gamma$-enolase in CD68-positive cells in GBM tissues. Representative images of triple immunofluorescence staining for cathepsin X (green), $\gamma$-enolase NSE-P2 (red), and marker of macrophages and microglia (CD68-purple) show overlapping expression of cathepsin $\mathrm{X}$ and $\gamma$-enolase NSE-P2 in the CD68-positive cells. The cell nuclei were counterstained with Hoechst 33258 (Hoechst, blue). Scale bar $=50 \mu \mathrm{m}$. 
A

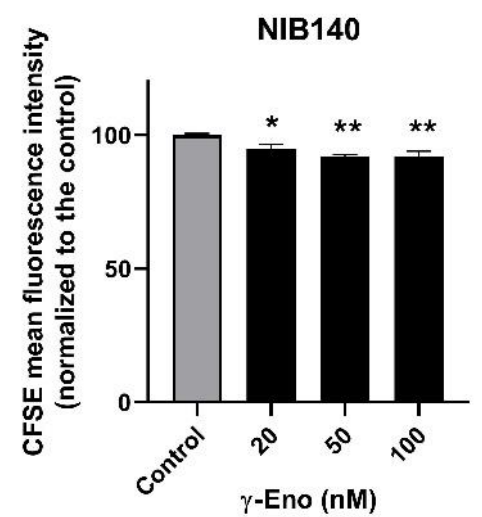

B

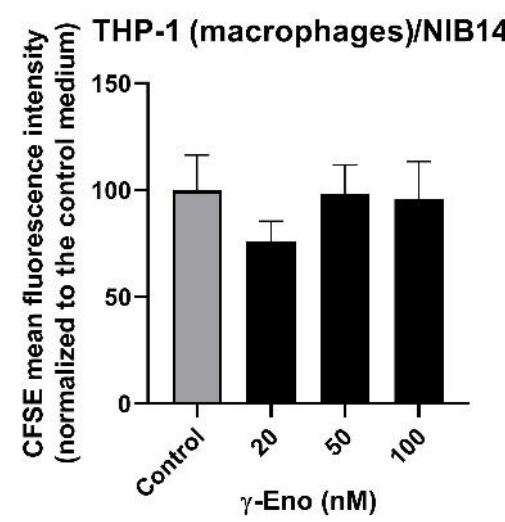

C

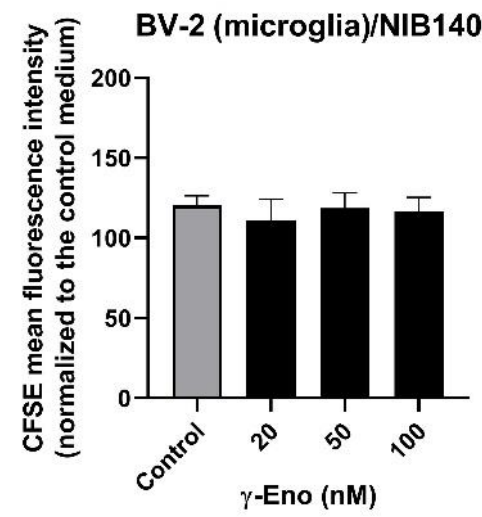

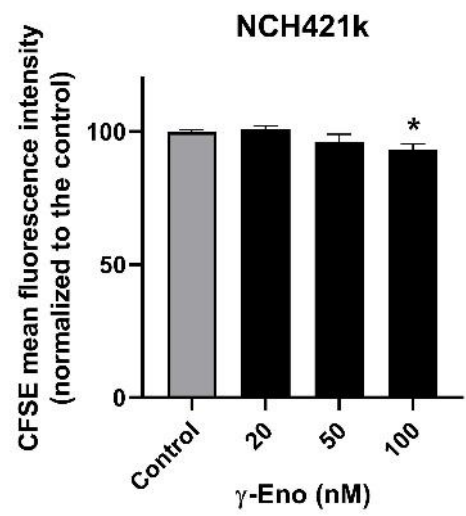
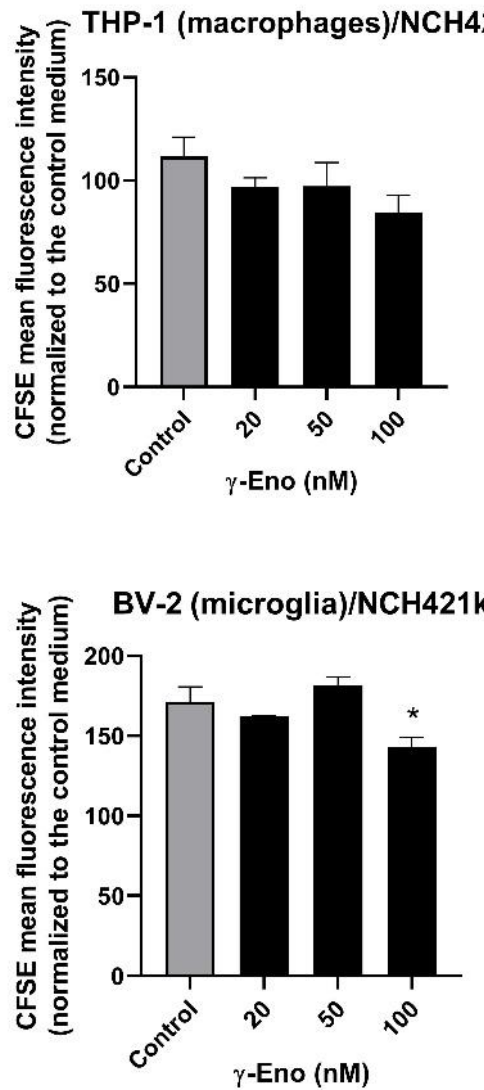

Figure 6. Effects of the $\gamma$-Eno peptide on proliferation of GBM cells, GSCs, and GBM-associated cells. GBM cells NIB140, GSCs NCH421k (A), as well as differentiated macrophage THP-1 cells (B) and BV-2 microglial cells (C) exposed to the NIB140- and NCH421k-conditioned media were treated with increasing concentrations of the $\gamma$-enolase peptide, C-terminal 30-amino-acid sequence of human brain $\gamma$-enolase ( $\gamma$-Eno). Cell proliferation was evaluated using CFSE staining and flow cytometry. The control means a blank culture GBM cell/GSC medium without addition of $\gamma$-Eno (A). The control medium is a blank GBM cell/GSC medium without soluble molecules secreted from GBM cells/GSCs and without addition of $\gamma$-Eno $(\mathbf{B}, \mathbf{C})$. The data are presented as the means \pm SEM. ${ }^{*} p<0.05,{ }^{* *} p<0.01$.

\section{Discussion}

We found upregulated levels of cathepsin X in recurrent and de novo GBM tissues compared to less malignant low-grade gliomas and nontumor brain tissues. This is consistent with a previous finding that high expression of cathepsin $X$ correlates with advanced tumor 
stages in several types of cancer, including prostate, colon, pancreatic, and neuroendocrine cancers [54-57]. To investigate the association of cathepsin X with GBM intertumoral heterogeneity, we analyzed the gene expression of cathepsin $X$ in four different GBM subtypes and found expression in all the subtypes and no significant differences between the subtypes, except for the lowest expression of cathepsin $X$ in the mixed subtype.

Since increased expression and activity of cathepsin $X$ have been observed in GBM, targeting this enzyme with specific inhibitors opens a new possibility for the treatment of this disease. Several peptidase inhibitors are already in clinical use [58,59], but this is not the case for the inhibitors of cysteine cathepsins. Potent, selective, reversible, and nontoxic inhibitors of cathepsin X were recently developed [60], and one of them, compound Z7, was tested in the present study. In addition, AMS36 was used as an irreversible selective inhibitor of cathepsin $X[61,62]$. A previous study also suggests that the cathepsin $X$ inhibitor AMS36 can cross the blood-brain barrier. The potency of the cathepsin $X$ inhibitor was determined in male Wistar rats treated with AMS36 at a dose of $50 \mathrm{mg} / \mathrm{kg}$ (i.p.). Decreased cathepsin $X$ activity was detected in the cerebellar extracts after two days of AMS36 administration compared with DMSO, indicating that AMS36 crossed the bloodbrain barrier [41]. In this study, by selectively inhibiting cathepsin X using these inhibitors, we demonstrated that cathepsin $X$ promotes viability and proliferation of patient-derived GBM cells, but not of GSCs. Moreover, we showed that cathepsin X promotes GBM cell invasion. Invasive growth of residual GBM cells in the surrounding brain tissues is one of the main reasons for the poor prognosis in GBM. Similarly to neural progenitor cells and adult brain stem cells, GBM cells often actively migrate along blood vessels and white matter pathways [63]. Our findings are in line with other studies that showed that cathepsin $X$ is actively involved in cell signaling and promotes cancer cell adhesion, migration, and invasion $[23,57,64,65]$. Nonetheless, the molecular mechanisms of these effects remain to be elucidated.

Cathepsin $\mathrm{X}$ is expressed in cells of the immune system and in the brain, e.g., in glial cells, neurons, oligodendrocytes, and ependymal cells [23,35,37-40], in which it cleaves various molecular targets involved in signal transduction, growth, maturation, adhesion, cell-cell communication, proliferation and migration of immune cells. Among nonneoplastic cells, TAMs and microglia have emerged as critical regulators of GBM growth, invasion, angiogenesis, and treatment resistance $[12,17,19,21]$. We found elevated expression of cathepsin X in GBM cells and of TAMs and microglia in GBM tissues, which is consistent with previous studies in other types of cancer showing that cathepsin $X$ is produced by both cancer cells and TAMs in the TME, influencing cellular crosstalk, cancer proliferation and invasion [57]. As macrophages are found in perivascular GSC niches in GBM [19,21], this may explain the perivascular expression of cathepsin $X$ in our previous study [34]. We showed that inhibition of cathepsin $X$ decreased the viability of macrophages and microglia cultured in conditioned media of GBM cells and GSCs, suggesting the role of cathepsin X in the survival of tumor-supporting TAMs and microglia. By inhibiting cathepsin $X$, we could not only inhibit GBM cell viability, but also tumor-supporting immune cells such as macrophages and microglia, thereby inhibiting GBM progression. Further studies in more complex tumor models where the immune compartment is maintained, such as organoids or mouse models, are needed to analyze the effects of cathepsin $\mathrm{X}$ inhibitors on cancer and immune cells.

The target of cathepsin $X$ carboxypeptidase activity in brain cells is $\gamma$-enolase, which plays an important role in aerobic glycolysis and cell proliferation $[45,66,67]$; $\gamma$-enolase is overexpressed in neurogenic and neuroendocrine tumors [68], and in this study and in others [49], it was shown that it is also expressed in GBM tissues. High levels of $\gamma$-enolase are associated with increased aerobic glycolysis, proliferation, and survival of cancer cells [46,49]; $\gamma$-enolase also acts as a neurotrophic-like factor and supports growth, survival, and differentiation of neurons $[45,66,67]$. The intact $C$-terminus of $\gamma$-enolase is responsible for the neurotrophic function and is not part of the catalytic element involved in cell glycolysis. It has been shown previously that the peptide mimicking the intact $C$-terminal 
end of $\gamma$-enolase promotes neuronal survival and neurite outgrowth through activation of the phosphatidylinositol 3-kinase/Akt and mitogen-activated protein kinase/extracellular signal-regulated kinase signaling pathways [44]. Similarly, we observed that the $\gamma$-Eno peptide mimicking the $C$-terminus of $\gamma$-enolase increased the proliferation of GBM cells, GSCs, and GBM-associated immune cells in vitro.

Cathepsin $X$ cleaves the $C$-terminal dipeptide of $\gamma$-enolase, which abolishes its neurotrophic activity $[42,44]$. In this study, we showed that there is a link between cathepsin $X$ and $C$-terminal cleavage of $\gamma$-enolase in the progression of GBM. Namely, cathepsin $X$ activity was upregulated in GBM tissues and correlated with decreased levels of the intact active form of $\gamma$-enolase. In comparison, the levels of both forms, intact active and total $\gamma$-enolase, were similar in nontumor brain tissues. Moreover, colocalization of cathepsin $\mathrm{X}$ with the total form of $\gamma$-enolase was observed in GBM tissues, particularly in TAMs and microglia. The latter is consistent with our previous study in which a significantly different colocalization pattern of both forms of $\gamma$-enolase was observed in brain tissues. Namely, in a mouse model of Alzheimer's disease, the C-terminally cleaved form of $\gamma$-enolase was associated with cathepsin $X$ in the immediate plaque vicinity, whereas the intact active form was observed in close proximity of the senile plaque, with preferential localization in microglia, which are the resident immune cells in the brain [40]. Nevertheless, the present data suggest that cathepsin $X$ cleaves the $C$-terminal end of $\gamma$-enolase in GBM, whereas $\gamma$-enolase remains intact in nontumor tissues, where lower cathepsin $X$ protein levels and activity occur.

Cathepsins have been shown to be strong predictive biomarkers for GBM patient survival $[27,28,33]$. In this study, high levels of cathepsin $X$ do not correlate with survival of GBM patients, although we showed by its selective inhibition that cathepsin $X$ promotes viability of GBM cells and GBM-associated macrophages and microglia as well as proliferation and invasion of GBM cells. This may be due to the fact that cathepsin $X$ can cleave and interact with multiple molecular targets that are involved in different cellular processes [23]. For example, with respect to $\gamma$-enolase, cathepsin $X$ cleaves the $C$-terminal amino acids of $\gamma$-enolase and presumably neutralizes the proliferative effect of intact active $\gamma$-enolase on GBM cells, GSCs, and especially tumor-associated microglia as shown in our study. Thus, cathepsin $X$ also exerts antitumor activity and likely counterbalances tumor-promoting effects.

Taken together, cathepsin X is involved in human GBM progression. Further studies on the molecular mechanisms of cathepsin $X$ and its target $\gamma$-enolase are needed to explore its potential for antitumor therapies.

\section{Materials and Methods}

\subsection{Patient Samples}

Human tissue samples were obtained from patients with LGG (WHO grades I and II) and GBM (WHO grade IV) operated at the Department of Neurosurgery, University Medical Centre Ljubljana, Slovenia. We also obtained 16 tissue samples of nontumor brain tissues. Tumor diagnoses were established using the standard histopathology protocols at the Institute of Pathology of the Medical Faculty, University of Ljubljana. The clinical data and tumor characteristics (histopathological and molecular data) were provided by the Department of Neurosurgery and the Institute of Pathology of the Medical Faculty, University of Ljubljana, Slovenia. The study was approved by the National Medical Ethics Committee of the Republic of Slovenia (approval Nos. 0120-190/2018/23 and 0120-190/2018/4). Written informed consent was obtained from the patients and/or their authorized representatives in accordance with the Declaration of Helsinki.

\subsection{Establishment of Primary GBM Cells}

To isolate the primary GBM cells, fresh GBM tumor tissue biopsies were minced with scalpels in high-glucose Dulbecco's modified Eagle's medium (DMEM) (Hyclone, GE Healthcare, Chicago, IL, USA) supplemented with 10\% fetal bovine serum 
(FBS; Gibco, Thermo Fisher Scientific, Waltham, MA, USA), 2 mM L-glutamine, and $1 \times$ penicillin/streptomycin (both: Sigma-Aldrich, St. Louis, MO, USA) and seeded in six-well cell culture plates (Corning, New York, NY, USA). Outgrowing cells were detached with a $0.25 \%$ trypsin-EDTA solution (Gibco) and transferred to T25 or T75 cell culture flasks (Corning). The cells were passaged at least three times in this manner and expanded for subsequent analyses. GBM cells were tested using qPCR for expression of GBM cell markers, including CD44, GFAP, and tubulin beta III (TUBB3).

To isolate GSCs, tumor tissue pieces were digested in a digestion buffer $(200 \mathrm{U} / \mathrm{mL}$ collagenase II and collagenase IV (both: Gibco) in Neurobasal Medium (Invitrogen, Life Technologies, Carlsbad, CA, USA)). Cell suspensions were filtered using a cell strainer with $100 \mu \mathrm{m}$ pores (BD Falcon, Corning, NY, USA). Single cells were collected and resuspended in complete Neurobasal Medium containing $2 \mathrm{mM}$ L-glutamine, $1 \times$ penicillin/streptomycin (both: Sigma-Aldrich), 1× B-27 (Invitrogen), $1 \mathrm{U} / \mathrm{mL}$ heparin (Sigma-Aldrich), $20 \mathrm{ng} / \mathrm{mL}$ bFGF and EGF (both: Invitrogen). GSCs were cultured as floating spheres in an untreated cell culture flask (Sarstedt Inc., Nümbrecht, Germany). Once these GSC spheres reached $200 \mu \mathrm{m}$ in diameter, they were dissociated using TrypLE Express (Gibco). GSCs were tested using immunofluorescence and qPCR to express GSC markers, including CD133 (PROM1), SOX2, NOTCH, and OCT4.

\subsection{GBM and Astrocyte Cell Cultures}

GBM stem cell line NCH421k was obtained from CLS (Cell Lines Service GmbH, Eppelheim, Germany). NCH421k cells were grown as floating spheres in complete Neurobasal Medium. All the cell lines were maintained at $37{ }^{\circ} \mathrm{C}$ with $5 \% \mathrm{CO}_{2}$ and $95 \%$ humidity. Once these GSC spheres reached $200 \mu \mathrm{m}$ in diameter, they were dissociated using TrypLE Express (Gibco).

NIB140 cells were the primary patient-derived GBM cells obtained from freshly resected tumor biopsies of the GBM patients operated at University Medical Centre Ljubljana and grown in monolayers in cell culture flasks as described above. All the cell cultures were tested for mycoplasma contamination using a MycoAlert Mycoplasma Detection Kit (Lonza, Basel, Switzerland).

NIB140 and NCH421k cells were tested for gene expression of several stem cell markers, including CD133 (PROM1), SOX2, OLIG2, NOTCH1, OCT4, and CD15, as well as differentiation markers GFAP and TUBB3. Real-time quantitative polymerase chain reaction (RT-qPCR) was used to determine relative mRNA expression of candidate genes (see the next paragraph for details). All the GBM stem cell markers were highly expressed in NCH421k cells and upregulated in comparison to NIB140 cells. NIB140 cells expressed higher levels of differentiation markers GFAP and TUBB3 in comparison to NCH421k cells (Figure S3).

Human astrocytes were purchased from ScienCell Research Laboratories (Carlsbad, CA, USA) and cultured in Astrocyte Medium (ScienCell) supplemented with 2\% FBS (ScienCell), $1 \%$ astrocyte growth supplement (ScienCell), and 1\% penicillin/streptomycin (ScienCell).

\subsection{Microglia and Macrophage Cell Cultures}

Mouse microglial BV-2 cells were a generous gift from Dr. Alba Minelli (University of Perugia, Perugia, Italy). BV-2 cells were cultured in DMEM (Sigma-Aldrich) supplemented with 10\% FBS (Gibco), $2 \mathrm{mM}$ L-glutamine, $50 \mathrm{U} / \mathrm{mL}$ penicillin, and $50 \mu \mathrm{g} / \mathrm{mL}$ streptomycin (Sigma-Aldrich). The cells were maintained at $37{ }^{\circ} \mathrm{C}$ in a humidified atmosphere of $95 \%$ air and $5 \% \mathrm{CO}_{2}$. Confluent cells were subcultured twice or thrice weekly using $0.25 \%$ trypsin.

Human THP-1 monocytes were obtained from ATCC (American Type Culture Collection: TIB-202) and grown in suspension in advanced RPMI (Gibco, Thermo Fisher) supplemented with $10 \%(v / v)$ FBS in a humidified, $37^{\circ} \mathrm{C}, 5 \% \mathrm{CO}_{2}$ incubator. THP-1 cells were kept at a minimum density of $3 \times 10^{5}$ cells $/ \mathrm{mL}$ and passaged when reaching $8 \times 10^{5}$ cells $/ \mathrm{mL}$. For differentiation, phorbol 12-myristate 13-acetate (PMA) (Sigma-Aldrich) was added to a final concentration of $100 \mathrm{nM}$. After $48 \mathrm{~h}$, the PMA-supplemented medium was removed, 
the cells were washed with PBS and treated with GBM and GSC-conditioned media for further analysis.

\subsection{Coculture Model}

To test the effect of soluble factors secreted by GBM, differentiated THP-1 or BV-2 cells were cultured in the complete medium and treated for $48 \mathrm{~h}$ with the supernatants of patient-derived GBM cells (NIB140) and GSCs (NCH421k) in the absence or presence of cathepsin X inhibitors AMS36 and Z7 (1.5-20 $\mu \mathrm{M})$ and the $\gamma$-Eno peptide (20-100 nM). After transfer of the GBM cell- and GSC-conditioned media, the cells were examined for cell viability and proliferation index.

\subsection{Real-Time Quantitative PCR}

The tissue samples were snap frozen and stored in liquid nitrogen for further analyses. Total RNA from the tissues and cells was isolated using an AllPrep DNA/RNA/Protein Mini Kit (Qiagen, Germantown, MD, USA) according to the manufacturer's instructions; cDNA was generated from $1 \mu \mathrm{g}$ of total RNA of each sample using a High-Capacity cDNA Reverse Transcription Kit (Thermo Fischer Scientific). RT-qPCR was performed to evaluate the mRNA level of genes in our samples. Fluidigm BioMark HD System RT-PCR (Fluidigm Corporation, San Francisco, CA, USA) and 48.48 Dynamic Arrays IFC, where cDNA of 42 samples and 24 TaqMan Gene Expression assays (ThermoFisher Scientific, see Table 1), were mixed pairwise in nanoliter chambers to enable parallel analysis of 2304 reactions. Visualization and analysis of the RT-qPCR results were performed using the Biomark Data Collection software, the Fluidigm RT-qPCR analysis software (both: Fluidigm Corporation), and the quantGenius software [69]. Relative copy numbers of cDNA were normalized to housekeeping genes HPRT1 and GAPDH. Statistical analyses were performed with one-way ANOVA in GraphPad Prism (GraphPad Software Inc., La Jolla, CA, USA).

For PCR analysis, 43 de novo GBM, five recurrent GBM (GBM rec), 14 LGG, 16 nontumor brain $(\mathrm{N})$ tissue samples were analyzed. Moreover, differentiated GBM cells $(n=17)$ and GSCs $(n=6)$ were isolated from GBM tumor biopsies to analyze the relative mRNA expression of cathepsin X. GBM samples and the corresponding clinical data are listed in Table S2.

\subsection{Gene Expression Data Analyses \\ 4.7.1. GBM Subtyping}

The fifteen selected genes, COL1A2, COL1A, TGFB1, THBS1, DAB2, S100A4, P2RX7, STMN4, SOX10, ERBB3, ACSBG1, KCBF1, OLIG2, NOTCH1, and NFKB1 were used to cluster GBM samples (tissues and cells) into four GBM subtypes: mesenchymal (MES), proneural (PN), classical (CL), and mixed (MIX) [48]. Since the number of subtypes (clusters) was known in advance, we used k-means clustering to partition the expression profiles of the selected genes in one of the four subtypes. The analysis was performed as described in [48] using the R software (version 4.0.3) and its libraries factoextra and cluster [70,71].

\subsubsection{Differentially Expressed Genes among the GBM Samples}

Differences in the mRNA expression levels of cathepsin X between the GBM samples (tissues and cells) and the previously defined GBM subtypes (mesenchymal-MES, proneural-PN, classical—CL, and MIX - mixed) were analyzed. To minimize the effect of genes with low expression, we first removed them from the analysis by placing the $\mathrm{Ct}$ values $>40$ as zero. We plotted boxplots to visually assess the differences and variability of the cathepsin $X$ gene expression and then assessed the potential difference between sample types and subtypes using analysis of variance (to determine the homogeneity of variance) followed by Tukey's post hoc tests. The analyses were conducted in R version 4.0.3. 
Table 1. List of TaqMan gene expression assays (Thermo Fisher Scientific) used for RT-qPCR.

\begin{tabular}{|c|c|c|c|}
\hline Gene Name & Assay ID & Assay Type & $\#$ \\
\hline GAPDH & Hs99999905_m1 & FAM-MGB, S(250rxns) & 4331182 \\
\hline HPRT1 & Hs02800695_m1 & FAM-MGB, XS(75rxns) & 4453320 \\
\hline COL1A2 & Hs01028956_m1 & FAM-MGB, XS(75rxns) & 4331182 \\
\hline COL1A & Hs00164004_m1 & FAM-MGB, XS(75rxns) & 4331182 \\
\hline TGFBI & Hs00998133_m1 & FAM-MGB, XS(75rxns) & 4331182 \\
\hline THBS1 & Hs00962908_m1 & FAM-MGB, XS(75rxns) & 4331182 \\
\hline DAB2 & Hs01120074_m1 & FAM-MGB, XS(75rxns) & 4331182 \\
\hline S100A4 & Hs00243202_m1 & FAM-MGB, XS(75rxns) & 4331182 \\
\hline P2RX7 & Hs00175721_m1 & FAM-MGB, XS(75rxns) & 4331182 \\
\hline STMN4 & Hs00229288_m1 & FAM-MGB, XS(75rxns) & 4331182 \\
\hline SOX10 & Hs00366918_m1 & FAM-MGB, XS(75rxns) & 4331182 \\
\hline ERBB3 & Hs00176538_m1 & FAM-MGB, XS(75rxns) & 4331182 \\
\hline ACSBG1 & Hs00209500_m1 & FAM-MGB, XS(75rxns) & 4331182 \\
\hline KCNF1 & Hs00266908_s1 & FAM-MGB, XS(75rxns) & 4331182 \\
\hline OLIG2 & Hs00377820_m1 & FAM-MGB, XS(75rxns) & 4331182 \\
\hline NOTCH1 & hs01062014_m1 & FAM-MGB, XS(75rxns) & 4331182 \\
\hline NFKB1 & Hs00765730_m1 & FAM-MGB, XS(75rxns) & 4331182 \\
\hline CD133 (PROM1) & Hs00195682_m1 & FAM-MGB, XS(75rxns) & 4331182 \\
\hline SOX2 & Hs01053049_s1 & FAM-MGB, XS(75rxns) & 4331182 \\
\hline OCT4 (POU5F1B) & Hs01596605_s1 & FAM-MGB, XS(75rxns) & 4331182 \\
\hline CD15 (FUT4) & Hs01106466_s1 & FAM-MGB, XS(75rxns) & 4331182 \\
\hline GFAP & Hs00909233_m1 & FAM-MGB, XS(75rxns) & 4331182 \\
\hline TUB33 & Hs00801390_s1 & FAM-MGB, XS(75rxns) & 4331182 \\
\hline Cathepsin X (CTSZ) & Hs00938366_m1 & FAM-MGB, XS(75rxns) & 4331182 \\
\hline
\end{tabular}

\subsubsection{Survival Analysis}

Cox proportional hazards regression was calculated to assess survival in the GBM sample cohorts of different groups. High and low cathepsin X expression groups were determined based on the median expression of cathepsin X. All the analyses were performed in R software version 4.0.3. Logrank test was used to evaluate the statistically significant difference.

\subsection{Immunofluorescence}

Formalin-fixed and paraffin-embedded tissue sections from six GBM (de novo, WHO grade IV) patients and one noncancerous brain tissue were prepared at the Institute of Pathology and used for immunofluorescence analyses (see Table S1).

The tumor sections were deparaffinized in xylene and rehydrated in ethanol. Heatmediated antigen retrieval was achieved with a sodium citrate buffer ( $\mathrm{pH}$ 6.0). Nonspecific binding sites were blocked with a solution of $10 \%$ FBS (Gibco; $v / v), 0.1 \%$ Triton X-100 (Sigma-Aldrich; $v / v$ ), and 1\% BSA (Sigma-Aldrich; $w / v$ ) in $1 \times$ PBS (Gibco) for $1 \mathrm{~h}$. After blocking, the sections were incubated with the TrueBlack reagent (Biotium, Fremont, CA, USA) diluted 1:20 in 70\% ethanol for $30 \mathrm{~s}$ to block autofluorescence due to lipofuscin and blood components. The tissue sections were incubated with the primary antibodies (see Table 2) diluted in $1 \times$ PBS containing $1 \%$ BSA overnight at $4{ }^{\circ} \mathrm{C}$. After washing with $0.5 \%$ BSA in $1 \times$ PBS, the tissues were incubated with the secondary antibodies (see Table 3) in $1 \times$ PBS containing $1 \%$ BSA for $1 \mathrm{~h}$ at room temperature. The nuclei were stained with a Hoechst 33258 solution (1:1000; Sigma-Aldrich) for $5 \mathrm{~min}$ at room temperature. After washing with $1 \times$ PBS, the tissue sections were mounted in a ProLong Gold Antifade mounting solution (Invitrogen), coverslipped, and sealed with nail polish Confocal imaging was performed using a confocal microscope (SP8 TCS) and the LAS X Life Sciences software (both: Leica, Wetzlar, Germany) at 100 $\times$ and $200 \times$ magnification. Negative control staining was performed in the absence of the primary antibodies. 
Table 2. List of the primary antibodies.

\begin{tabular}{cc}
\hline Primary Antibodies & Source \\
\hline Goat polyclonal anti-cathepsin X & R\&D System (AG934) \\
Mouse monoclonal anti-Iba1 & Abcam (ab15690) \\
Rabbit polyclonal anti-CD68 & Atlas antibodies (HPA048982) \\
Mouse monoclonal anti-SOX2 & Abcam (ab171380) \\
Rabbit polyclonal anti-CD133 & Abcam (ab19898) \\
Rabbit polyclonal anti-GFAP & Abcam (ab211271) \\
Mouse monoclonal anti- $\gamma$-enolase (NSE-P1) & Santa Cruz Biotechnology (sc-21738) \\
Mouse monoclonal anti- $\gamma$-enolase (NSE-P2) & Santa Cruz Biotechnology (sc-21737) \\
Mouse monoclonal anti- $\gamma$-enolase (D-7) & Santa Cruz Biotechnology (sc-376375)
\end{tabular}

Table 3. List of the secondary antibodies.

\begin{tabular}{ccc}
\hline Secondary Antibodies & Source & Dilution \\
\hline Donkey anti-goat IgG (H+L) Highly Cross-Adsorbed \\
Secondary Antibody, Alexa Fluor Plus 488 \\
$\begin{array}{c}\text { Donkey anti-mouse IgG (H+L) Highly Cross-Adsorbed } \\
\text { Secondary Antibody, Alexa Fluor Plus 647 } \\
\text { Donkey anti-rabbit IgG (H+L) Highly Cross-Adsorbed } \\
\text { Secondary Antibody, Alexa Fluor Plus 546 } \\
\text { Donkey anti-mouse IgG (H+L) Highly Cross-Adsorbed } \\
\text { Secondary Antibody, Alexa Fluor Plus 546 }\end{array}$ & Thermo Fisher Scientific (A32814) & $1: 200$ \\
& Thermo Fisher Scientific (A32787) & $1: 200$ \\
$1: 200$ \\
\hline
\end{tabular}

\subsection{Protein Extraction from GBM Tissues and Nontumor Brain Tissues}

For analysis of the protein levels of cathepsin $\mathrm{X}$ and its activity, tissues were homogenized in ice-cold lysis buffer (0.05 $\mathrm{M}$ sodium acetate, pH 5.5, $1 \mathrm{mM}$ EDTA, $0.1 \mathrm{M} \mathrm{NaCl}$, $0.25 \%$ Triton $\mathrm{X}-100$ ) supplemented with a cocktail of phosphatase inhibitors (Thermo Fisher Scientific), then sonicated and centrifuged at $15,000 \times g$ at $4{ }^{\circ} \mathrm{C}$ for $15 \mathrm{~min}$ to collect the supernatant. Total protein concentration was determined with DC ${ }^{\mathrm{TM}}$ Protein Assay (Bio-Rad, Hercules, CA, USA). All the samples were kept at $-70{ }^{\circ} \mathrm{C}$ until they were used for analysis.

\subsection{Cathepsin X Activity}

Cathepsin $X$ activity was measured in tissue lysates and cell lysates with cathepsin X-specific intramolecularly quenched fluorogenic substrate Abz-Phe-Glu-Lys(Dnp)-OH synthesized by Jiangsu Vcare Pharmatech Co. (China). An aliquot of $50 \mu \mathrm{g}$ of the lysate proteins was incubated at $37^{\circ} \mathrm{C}$, followed by measurement of cathepsin $\mathrm{X}$ activity using $10 \mu \mathrm{M}$ Abz-Phe-Glu-Lys(Dnp)-OH. The fluorometric reaction was quantified at $37^{\circ} \mathrm{C}$ at an excitation wavelength of $320 \mathrm{~nm}$ and emission wavelength of $420 \mathrm{~nm}$ on a microplate reader (Tecan Safire2). The results are presented as a change in fluorescence as a function of time $(\Delta \mathrm{F} / \Delta \mathrm{t})$, and cathepsin $\mathrm{X}$ activity was expressed relative to the control.

\subsection{ELISAs}

The protein levels of cathepsin $X$ and $\gamma$-enolase in tissue lysates were determined using ELISA as previously reported [35]. For the cathepsin $\mathrm{X}$ protein levels, microtiter plates were coated with equal aliquots of goat polyclonal anti-cathepsin $\mathrm{X}$ antibody (RD Systems) in $0.01 \mathrm{M}$ carbonate/bicarbonate buffer, $\mathrm{pH} 9.6$, at $4{ }^{\circ} \mathrm{C}$. After blocking with $2 \%$ BSA in PBS, $\mathrm{pH} 7.4$, for $1 \mathrm{~h}$ at room temperature, the samples with equal protein amounts $(50 \mu \mathrm{g})$ or cathepsin $\mathrm{X}$ standards $(0-65 \mathrm{ng} / \mathrm{mL})$ were added. Following $2 \mathrm{~h}$ incubation at $37^{\circ} \mathrm{C}$, the wells were washed and filled with a mouse monoclonal anti-cathepsin X 3B10 antibody conjugated with horseradish peroxidase (HRP) in a blocking buffer. Mouse monoclonal 3B10 antibodies were prepared from a mouse hybridoma cell line as reported [35]. After a further $2 \mathrm{~h}$ incubation at $37^{\circ} \mathrm{C}, 200 \mu \mathrm{L} /$ well of $3,3^{\prime}, 5,5^{\prime}$-tetramethylbenzidine (TMB) substrate (Sigma-Aldrich) in $0.012 \% \mathrm{H}_{2} \mathrm{O}_{2}$ was added. After $15 \mathrm{~min}$, the reaction was 
stopped by adding $50 \mu \mathrm{L} /$ well of $2 \mu \mathrm{M} \mathrm{H}_{2} \mathrm{SO}_{4}$. The amount of protein was determined by measuring the absorbance at $450 \mathrm{~nm}$ using a microplate reader (Tecan Safire2), and the concentration of cathepsin $\mathrm{X}$ was calculated from the standard calibration curve. To measure active $\gamma$-enolase, microtiter plates were coated with equal aliquots of the protein in $0.01 \mathrm{M}$ carbonate/bicarbonate buffer, $\mathrm{pH} 9.6$, at $4{ }^{\circ} \mathrm{C}$. After blocking with $2 \%$ BSA in PBS, pH 7.4, for $1 \mathrm{~h}$ at room temperature, a mouse antibody against $C$-terminal $\gamma$-enolase (Santa Cruz Biotechnology) suitable for detecting its active form was added. Following $2 \mathrm{~h}$ incubation at $37^{\circ} \mathrm{C}$, the wells were washed and filled with an anti-mouse antibody conjugated with HRP. After further $2 \mathrm{~h}$ incubation at $37^{\circ} \mathrm{C}, 200 \mu \mathrm{g}$ /well of a TMB substrate in $0.012 \% \mathrm{H}_{2} \mathrm{O}_{2}$ was added. After $15 \mathrm{~min}$, the reaction was stopped by adding $50 \mu \mathrm{L}$ of $2 \mu \mathrm{M}$ $\mathrm{H}_{2} \mathrm{SO}_{4}$. The amount of cleaved substrate was determined by measuring the absorbance at $450 \mathrm{~nm}$, and the protein levels of cathepsin $X$ and $\gamma$-enolase were expressed relative to those in untreated cells (control).

\subsection{Cathepsin X Inhibitors and $\gamma$-Enolase C-Terminal Peptide}

The irreversible selective inhibitor of cathepsin X, AMS36, was synthesized according to the modified procedure of Sadaghiani et al. [61] in house [62]. The selective reversible inhibitor Z7 (1-(2,3-dihydrobenzo[b][1,4]dioxin-6-yl)-2-((4-(o-tolyl)-4H-1,2,4-triazol-3-yl)thio) ethan-1-one) was obtained from in-house compound library screening and was synthesized as described $[60,61]$. The C-terminal 30-amino-acid sequence of human brain $\gamma$-enolase $(\gamma$ Eno) was synthesized by Biosynthesis (Lewisville, TX, USA), here defined as the $\gamma$-enolase peptide (AKYNQLMRIEEELGDEARFAGHNFRNPSVL). The use of the concentration range of cathepsin $\mathrm{X}$ inhibitors and the $\gamma$-Eno peptide was based on previous studies $[40,60,65]$.

\subsection{Cell Viability Assay}

MTS [3-(4,5-dimethylthiazol-2-yl)-5-(3-carboxymetoxyphenyl)-2-(4-sulfophenyl)-2Htetrazolium] colorimetric assay was used to measure viability of GBM cells. NIB140 $\left(5 \times 10^{3}\right)$ and NCH421k $\left(8 \times 10^{3}\right)$ cells were seeded into wells of a 96-well microplate (Thermo Fisher Scientific), and after overnight incubation, they were treated with a range of concentrations of cathepsin X inhibitors (Z7 and AMS36; 0.1-20 $\mu \mathrm{M}$ ) and the $\gamma$-enolase peptide (20-100 $\mathrm{nM}$ ) for $48 \mathrm{~h}$. DMSO (final concentration, 0.25\%; Sigma-Aldrich) and the culture medium were used as solvent controls for cathepsin $\mathrm{X}$ inhibitors and the $\gamma$-enolase peptide, respectively. The MTS reagent (Promega, Madison, WI, USA) was then added to the wells of a 96-well microplate and, after incubation, absorbance of formazan was measured at $490 \mathrm{~nm}$ on a Synergy Mx microplate reader (Biotek, Winooski, VT, USA). Cell viability (\%) was determined as the ratio of absorbance obtained in the presence of the tested compound to that in the solvent alone. Three independent experiments with three replicates per treatment were performed.

\subsection{Cell Proliferation Assay}

A CellTrace Cell Proliferation kit with the CellTrace CFSE reagent (Invitrogen) was used to determine cell proliferation. CFSE fluorescent dye stably incorporates into the cells, and the CFSE content of a cell is divided approximately by half each time the cell divides. By measuring CFSE-labeled cell fluorescence, cell proliferation can be determined. GBM cells were stained with the CellTrace CFSE reagent at a concentration of $1 \mu \mathrm{M}$ in a cell suspension according to the manufacturer's protocol. NIB140 $\left(20 \times 10^{3}\right)$ and NCH421k $\left(10 \times 10^{3}\right)$ CFSE-labeled cells were seeded into 24 -well culture plates (Corning), respectively. After overnight incubation, the cells were treated with a range of concentrations of cathepsin X inhibitors (Z7 and AMS36; 5-20 $\mu \mathrm{M}$ ) and the $\gamma$-enolase peptide (20-100 nM) for $48 \mathrm{~h}$. DMSO (final concentration, 0.25\%; Sigma-Aldrich) and the culture medium were used as solvent controls for cathepsin $X$ inhibitors and the $\gamma$ enolase peptide, respectively. Temozolomide (TMZ; Sigma-Aldrich) in a concentration of $100 \mu \mathrm{M}$ was used as the positive control. The cells were harvested using TrypLE Express (Gibco), and the mean fluorescence intensities of the cells were measured in the B1 
channel using a MACSQuant Analyzer 10 flow cytometer and MACSQuantify Software V3 (both: Miltenyi Biotec, Bergisch Gladbach, Germany). The obtained data were analyzed in FlowJo software V10 (Becton Dickinson, Franklin Lakes, NJ, USA). The mean fluorescence intensity of CFSE reagent staining was normalized to the solvent control. Three independent experiments with two replicates per treatment were performed.

\subsection{Statistical Analyses}

Tukey's post hoc test, one-way ANOVA test with Dunnett's multiple comparison, unpaired t-test with Welch's t-correction, and multiple t-test followed by a two-stage linear step-up procedure of the Benjamini, Krieger, and Yekutieli correction were used to perform statistical analyses in GraphPad Prism software (GraphPad Software Inc., La Jolla, CA, USA) version 8 . $p$-values $<0.05$ were considered to indicate significant differences. The $p$-values were expressed within the Figures as follows: ${ }^{* * *} p<0.0001,{ }^{* * *} p<0.001$, ** $p=0.001-0.01,{ }^{*} p=0.01-0.05$.

Supplementary Materials: The following supporting information can be downloaded at https:/ /www. mdpi.com/article/10.3390/ijms23031784/s1. References [72-75] are cited in Supplementary Method 1.

Author Contributions: Conceptualization, B.M., M.N., J.K., T.L.T., A.P. (Anja Pišlar), and B.B.; formal analysis, B.M., A.H., M.N., J.M., A.P. (Andrej Porčnikand), A.R., A.P. (Anja Pišlar) and B.B.; funding acquisition, S.G., J.K, T.L.T., A.P. (Anja Pišlar) and B.B.; investigation, B.M., A.H., M.N., J.M., A.P.(Andrej Porčnikand), A.R., V.Ž., U.P.F., D.K., N.Z., S.G., J.K., T.L.T., A.P. (Anja Pišlar), and B.B.; methodology, B.M., A.H., M.N., J.M., A.P. (Andrej Porčnikand), A.R., V.Ž., U.P.F., D.K., N.Z., A.P. (Anja Pišlar) and B.B.; visualization, B.M., A.H., M.N., A.R., A.P. (Anja Pišlar) and B.B.; writingoriginal draft preparation, B.M., A.H., M.N., A.P. (Anja Pišlar) and B.B.; writing-review and editing, B.M., M.N., U.P.F., D.K., N.Z., V.Ž., S.G., J.K., T.L.T., A.P. (Anja Pišlar) and B.B. All authors have read and agreed to the published version of the manuscript.

Funding: This work was supported by the Slovenian Research Agency (grant programs P1-0245, P1-0207, P4-0127, and P1-0208, grant project J3-2526, postdoctoral project Z3-1870, Young Researcher grants to B.M. and A.H.) and the European Program of Cross-Border Cooperation Interreg SloveniaItaly TRANSGLIOMA.

Institutional Review Board Statement: The study was conducted in accordance with the Declaration of Helsinki and approved by the National Medical Ethics Committee of the Republic of Slovenia (approval Nos. 0120-190/2018/23 and 0120-190/2018/4).

Informed Consent Statement: All the patients signed written informed consent for the use of tumor samples for research, obtained by the operating neurosurgeon.

Data Availability Statement: All the data supporting the reported results can be provided upon request to the corresponding authors.

Acknowledgments: We would like to thank Cornelis van Noorden for critically reading the manuscript and Barbara Žvar Baškovič for technical assistance with experiments.

Conflicts of Interest: The authors declared no potential conflicts of interest with respect to the research, authorship, and/or publication of this article.

\section{References}

1. Louis, D.N.; Perry, A.; Wesseling, P.; Brat, D.J.; Cree, I.A.; Figarella-Branger, D.; Hawkins, C.; Ng, H.K.; Pfister, S.M.; Reifenberger, G.; et al. The 2021 WHO Classification of Tumors of the Central Nervous System: A summary. Neuro. Oncol. 2021, 23, 1231-1251. [CrossRef] [PubMed]

2. Wen, P.Y.; Weller, M.; Lee, E.Q.; Alexander, B.M.; Barnholtz-Sloan, J.S.; Barthel, F.P.; Batchelor, T.T.; Bindra, R.S.; Chang, S.M.; Chiocca, E.A.; et al. Glioblastoma in adults: A Society for Neuro-Oncology (SNO) and European Society of Neuro-Oncology (EANO) consensus review on current management and future directions. Neuro. Oncol. 2020, 22, 1073-1113. [CrossRef] [PubMed]

3. Louis, D.N.; Perry, A.; Reifenberger, G.; von Deimling, A.; Figarella-Branger, D.; Cavenee, W.K.; Ohgaki, H.; Wiestler, O.D.; Kleihues, P.; Ellison, D.W. The 2016 World Health Organization Classification of Tumors of the Central Nervous System: A summary. Acta Neuropathol. 2016, 131, 803-820. [CrossRef] [PubMed] 
4. $\quad$ Stupp, R.; Mason, W.P.; Van Den Bent, M.J.; Weller, M.; Fisher, B.; Taphoorn, M.J.B.; Belanger, K.; Brandes, A.A.; Marosi, C.; Bogdahn, U.; et al. Radiotherapy plus concomitant and adjuvant temozolomide for glioblastoma. N. Engl. J. Med. 2005, 352, 987-996. [CrossRef]

5. Lah, T.T.; Novak, M.; Breznik, B. Brain malignancies: Glioblastoma and brain metastases. Semin. Cancer Biol. 2020, 60, 262-273. [CrossRef]

6. Stupp, R.; Taillibert, S.; Kanner, A.; Read, W.; Steinberg, D.M.; Lhermitte, B.; Toms, S.; Idbaih, A.; Ahluwalia, M.S.; Fink, K.; et al Effect of tumor-treating fields plus maintenance temozolomide vs maintenance temozolomide alone on survival in patients with glioblastoma: A randomized clinical trial. J. Am. Med. Assoc. 2017, 318, 2306-2316. [CrossRef]

7. Teng, J.; Da Hora, C.C.; Kantar, R.S.; Nakano, I.; Wakimoto, H.; Batchelor, T.T.; Antonio Chiocca, E.; Badr, C.E.; Tannous, B.A. Dissecting inherent intratumor heterogeneity in patient-derived glioblastoma culture models. Neuro. Oncol. 2017, 19, 820-832. [CrossRef]

8. Molina, E.S.; Pillat, M.M.; Moura-Neto, V.; Lah, T.T.; Ulrich, H. Glioblastoma stem-like cells: Approaches for isolation and characterization. J. Cancer Stem Cell Res. 2014, 2, e1007. [CrossRef]

9. Lathia, J.D.; Mack, S.C.; Valentim, C.L.; Rich, J.N. Cancer stem cells in glioblastoma. Genes Dev. 2015, 29, 1203-1217. [CrossRef]

10. Majc, B.; Sever, T.; Zarić, M.; Breznik, B.; Turk, B.; Lah, T.T. Epithelial-to-mesenchymal transition as the driver of changing carcinoma and glioblastoma microenvironment. Biochim. Biophys. Acta - Mol. Cell Res. 2020, 1867, 118782. [CrossRef]

11. Broekman, M.L.; Maas, S.L.N.; Abels, E.R.; Mempel, T.R.; Krichevsky, A.M.; Breakefield, X.O. Multidimensional communication in the microenvirons of glioblastoma. Nat. Rev. Neurol. 2018, 14, 482-495. [CrossRef]

12. Quail, D.F.; Joyce, J.A. The Microenvironmental Landscape of Brain Tumors. Cancer Cell 2017, 31, 326-341. [CrossRef]

13. Chen, J.; Li, Y.; Yu, T.S.; McKay, R.M.; Burns, D.K.; Kernie, S.G.; Parada, L.F. A restricted cell population propagates glioblastoma growth after chemotherapy. Nature 2012, 488, 522-526. [CrossRef]

14. Galli, R.; Binda, E.; Orfanelli, U.; Cipelletti, B.; Gritti, A.; De Vitis, S.; Fiocco, R.; Foroni, C.; Dimeco, F.; Vescovi, A. Isolation and characterization of tumorigenic, stem-like neural precursors from human glioblastoma. Cancer Res. 2004, 64, 7011-7021. [CrossRef]

15. Osuka, S.; Van Meir, E.G. Overcoming therapeutic resistance in glioblastoma: The way forward. J. Clin. Investig. 2017, 127, 415-426. [CrossRef]

16. Verhaak, R.G.W.; Hoadley, K.A.; Purdom, E.; Wang, V.; Qi, Y.; Wilkerson, M.D.; Miller, C.R.; Ding, L.; Golub, T.; Mesirov, J.P.; et al. Integrated genomic analysis identifies clinically relevant subtypes of glioblastoma characterized by abnormalities in PDGFRA, IDH1, EGFR, and NF1. Cancer Cell 2010, 17, 98-110. [CrossRef]

17. Wang, L.B.; Karpova, A.; Gritsenko, M.A.; Kyle, J.E.; Cao, S.; Li, Y.; Rykunov, D.; Colaprico, A.; Rothstein, J.H.; Hong, R.; et al. Proteogenomic and metabolomic characterization of human glioblastoma. Cancer Cell 2021, 39, 509-528. [CrossRef]

18. Darmanis, S.; Sloan, S.A.; Croote, D.; Mignardi, M.; Chernikova, S.; Samghababi, P.; Zhang, Y.; Neff, N.; Kowarsky, M.; Caneda, C.; et al. Single-Cell RNA-Seq Analysis of Infiltrating Neoplastic Cells at the Migrating Front of Human Glioblastoma. Cell Rep. 2017, 21, 1399-1410. [CrossRef]

19. Glass, R.; Synowitz, M. CNS macrophages and peripheral myeloid cells in brain tumours. Acta Neuropathol. 2014, 128, 347-362. [CrossRef]

20. Morantz, R.A.; Wood, G.W.; Foster, M.; Clark, M.; Gollahon, K. Macrophages in experimental and human brain tumors. Part 2 Studies of the macrophage content of human brain tumors. J. Neurosurg. 1979, 50, 305-311. [CrossRef]

21. Zhou, W.; Ke, S.Q.; Huang, Z.; Flavahan, W.; Fang, X.; Paul, J.; Wu, L.; Sloan, A.E.; McLendon, R.E.; Li, X.; et al. Periostin secreted by glioblastoma stem cells recruits M2 tumour-associated macrophages and promotes malignant growth. Nat. Cell Biol. 2015, 17, 170-182. [CrossRef]

22. Chen, Z.; Feng, X.; Herting, C.J.; Garcia, V.A.; Nie, K.; Pong, W.W.; Rasmussen, R.; Dwivedi, B.; Seby, S.; Wolf, S.A.; et al. Cellular and molecular identity of tumor-associated macrophages in glioblastoma. Cancer Res. 2017, 77, 2266-2278. [CrossRef]

23. Kos, J.; Vižin, T.; Pečar Fonović, U.; Pišlar, A. Intracellular signaling by cathepsin X: Molecular mechanisms and diagnostic and therapeutic opportunities in cancer. Semin. Cancer Biol. 2015. [CrossRef]

24. Turk, V.; Stoka, V.; Vasiljeva, O.; Renko, M.; Sun, T.; Turk, B.; Turk, D. Cysteine cathepsins: From structure, function and regulation to new frontiers. Biochim. Biophys. Acta 2012, 1824, 68-88. [CrossRef]

25. Brix, K.; Dunkhorst, A.; Mayer, K.; Jordans, S. Cysteine cathepsins: Cellular roadmap to different functions. Biochimie 2008, 90, 194-207. [CrossRef]

26. Olson, O.C.; Joyce, J.A. Cysteine cathepsin proteases: Regulators of cancer progression and therapeutic response. Nat. Publ. Gr. 2015. [CrossRef]

27. Habič, A.; Novak, M.; Majc, B.; Lah Turnšek, T.; Breznik, B. Proteases Regulate Cancer Stem Cell Properties and Remodel Their Microenvironment. J. Histochem. Cytochem. 2021. [CrossRef]

28. Levicar, N.; Strojnik, T.; Kos, J.; Dewey, R.A.; Pilkington, G.J.; Lah T., T. Lysosomal enzymes, cathepsins in brain tumour invasion. J. Neurooncol. 2002, 58, 21-32. [CrossRef]

29. Rudzińska, M.; Parodi, A.; Soond, S.M.; Vinarov, A.Z.; Korolev, D.O.; Morozov, A.O.; Daglioglu, C.; Tutar, Y.; Zamyatnin, A.A The role of cysteine cathepsins in cancer progression and drug resistance. Int. J. Mol. Sci. 2019, 20, 3602. [CrossRef]

30. Benavides, F.; Perez, C.; Blando, J.; Contreras, O.; Shen, J.; Coussens, L.M.; Fischer, S.M.; Kusewitt, D.F.; Digiovanni, J.; Conti, C.J. Protective role of cathepsin L in mouse skin carcinogenesis. Mol. Carcinog. 2012, 51, 352-361. [CrossRef] 
31. Dennemärker, J.; Lohmüller, T.; Mayerle, J.; Tacke, M.; Lerch, M.M.; Coussens, L.M.; Peters, C.; Reinheckel, T. Deficiency for the cysteine protease cathepsin L promotes tumor progression in mouse epidermis. Oncogene 2009, 29, 1611-1621. [CrossRef] [PubMed]

32. López-Otín, C.; Matrisian, L.M. Emerging roles of proteases in tumour suppression. Nat. Rev. Cancer 2007, 7, 800-808. [CrossRef] [PubMed]

33. Lah T., T.; Durán Alonso, M.B.; Van Noorden, C.J.F. Antiprotease therapy in cancer: Hot or not? Expert Opin. Biol. Ther. 2006, 6, 257-279. [CrossRef] [PubMed]

34. Breznik, B.; Limbaeck Stokin, C.; Kos, J.; Khurshed, M.; Hira, V.V.V.; Bošnjak, R.; Lah T., T.; Van Noorden, C.J.F. Cysteine cathepsins B, X and K expression in peri-arteriolar glioblastoma stem cell niches. J. Mol. Histol. 2018, 49, 481-497. [CrossRef]

35. Kos, J.; Sekirnik, A.; Premzl, A.; Bergant Zavašnik, V.; Langerholc, T.; Turk, B.; Werle, B.; Golouh, R.; Repnik, U.; Jeras, M.; et al. Carboxypeptidases cathepsins X and B display distinct protein profile in human cells and tissues. Exp. Cell Res. 2005, 306, 103-113. [CrossRef]

36. Dolenc, I.; Štefe, I.; Turk, D.; Taler-Verčič, A.; Turk, B.; Turk, V.; Stoka, V. Human cathepsin X/Z is a biologically active homodimer. Biochim. Biophys. Acta-Proteins Proteomics 2021, 1869, 140567. [CrossRef]

37. Pišlar, A.; Kos, J. Cysteine cathepsins in neurological disorders. Mol. Neurobiol. 2014, 49, 1017-1030. [CrossRef]

38. Wendt, W.; Zhu, X.R.; Lübbert, H.; Stichel, C.C. Differential expression of cathepsin X in aging and pathological central nervous system of mice. Exp. Neurol. 2007, 204, 525-540. [CrossRef]

39. Stichel, C.C.; Luebbert, H. Inflammatory processes in the aging mouse brain: Participation of dendritic cells and T-cells. Neurobiol. Aging 2007, 28, 1507-1521. [CrossRef]

40. Hafner, A.; Glavan, G.; Obermajer, N.; Živin, M.; Schliebs, R.; Kos, J. Neuroprotective role of $\gamma$-enolase in microglia in a mouse model of Alzheimer's disease is regulated by cathepsin X. Aging Cell 2013, 12, 604-614. [CrossRef]

41. Pišlar, A.; Tratnjek, L.; Glavan, G.; Zidar, N.; Živin, M.; Kos, J. Neuroinflammation-Induced Upregulation of Glial Cathepsin X Expression and Activity in vivo. Front. Mol. Neurosci. 2020, 13, 1-17. [CrossRef]

42. Obermajer, N.; Doljak, B.; Jamnik, P.; Pečar Fonović, U.; Kos, J. Cathepsin X cleaves the C-terminal dipeptide of alpha- and gamma-enolase and impairs survival and neuritogenesis of neuronal cells. Int. J. Biochem. Cell Biol. 2009, 41, 1685-1696. [CrossRef]

43. Haque, A.; Polcyn, R.; Matzelle, D.; Banik, N.L. New insights into the role of neuron-specific enolase in neuro-inflammation, neurodegeneration, and neuroprotection. Brain Sci. 2018, 8, 33. [CrossRef]

44. Hafner, A.; Obermajer, N.; Kos, J. $\gamma$-Enolase C-terminal peptide promotes cell survival and neurite outgrowth by activation of the PI3K/Akt and MAPK/ERK signalling pathways. Biochem. J. 2012, 443, 439-450. [CrossRef]

45. Takei, N.; Kondo, J.; Nagaike, K.; Ohsawa, K.; Kato, K.; Kohsaka, S. Neuronal survival factor from bovine brain is identical to neuron-specific enolase. J. Neurochem. 1991, 57, 1178-1184. [CrossRef]

46. Vizin, T.; Kos, J. Gamma-enolase: A well-known tumour marker, with a less-known role in cancer. Radiol. Oncol. 2015, $49,217$. [CrossRef]

47. Behnan, J.; Stangeland, B.; Hosainey, S.A.M.; Joel, M.; Olsen, T.K.; Micci, F.; Glover, J.C.; Isakson, P.; Brinchmann, J.E. Differential propagation of stroma and cancer stem cells dictates tumorigenesis and multipotency. Oncogene 2017, 36, 570-584. [CrossRef]

48. Novak, M.; Koprivnikar Krajnc, M.; Hrastar, B.; Breznik, B.; Majc, B.; Mlinar, M.; Rotter, A.; Porčnik, A.; Mlakar, J.; Stare, K.; et al. CCR5-Mediated Signaling Is Involved in Invasion of Glioblastoma Cells in Its Microenvironment. Int. J. Mol. Sci. 2020, 21, 4199. [CrossRef]

49. Yan, T.; Skaftnesmo, K.O.; Leiss, L.; Sleire, L.; Wang, J.; Li, X.; Enger, P.T. Neuronal markers are expressed in human gliomas and NSE knockdown sensitizes glioblastoma cells to radiotherapy and temozolomide. BMC Cancer 2011, 11, 524. [CrossRef]

50. Expression of ENO2 in Cancer. The Human Protein Atlas. Available online: https://www.proteinatlas.org/ENSG00000111674 -ENO2/pathology (accessed on 5 January 2022).

51. Sehnal, D.; Bittrich, S.; Deshpande, M.; Svobodová, R.; Berka, K.; Bazgier, V.; Velankar, S.; Burley, S.K.; Koča, J.; Rose, A.S.

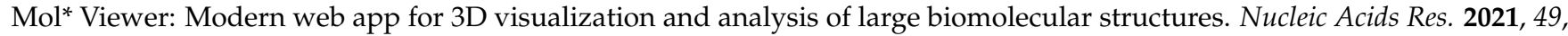
W431-W437. [CrossRef]

52. Chai, G.; Brewer, J.M.; Lovelace, L.L.; Aoki, T.; Minor, W.; Lebioda, L. Expression, purification and the 1.8 angstroms resolution crystal structure of human neuron specific enolase. J. Mol. Biol. 2004, 341, 1015-1021. [CrossRef]

53. Hafner, A.; Obermajer, N.; Kos, J. Gamma-1-syntrophin mediates trafficking of gamma-enolase towards the plasma membrane and enhances its neurotrophic activity. NeuroSignals 2011, 18, 246-258. [CrossRef]

54. Nägler, D.K.; Krüger, S.; Kellner, A.; Ziomek, E.; Menard, R.; Buhtz, P.; Krams, M.; Roessner, A.; Kellner, U. Up-regulation of cathepsin $\mathrm{X}$ in prostate cancer and prostatic intraepithelial neoplasia. Prostate 2004, 60, 109-119. [CrossRef]

55. Krueger, S.; Kalinski, T.; Hundertmark, T.; Wex, T.; Küster, D.; Peitz, U.; Ebert, M.; Nägler, D.K.; Kellner, U.; Malfertheiner, P.; et al Up-regulation of cathepsin X in Helicobacter pylori gastritis and gastric cancer. J. Pathol. 2005, 207, 32-42. [CrossRef]

56. Vizin, T.; Christensen, I.; Nielsen, H.; Kos, J. Cathepsin X in serum from patients with colorectal cancer: Relation to prognosis. Radiol. Oncol. 2012, 46, 207-212. [CrossRef]

57. Akkari, L.; Gocheva, V.; Kester, J.C.; Hunter, K.E.; Quick, M.L.; Sevenich, L.; Wang, H.W.; Peters, C.; Tang, L.H.; Klimstra, D.S.; et al. Distinct functions of macrophage-derived and cancer cell-derived cathepsin Z combine to promote tumor malignancy via interactions with the extracellular matrix. Genes Dev. 2014, 28, 2134-2150. [CrossRef]

58. Turk, B. Targeting proteases: Successes, failures and future prospects. Nat. Rev. Drug Discov. 2006, 5, 785-799. [CrossRef] 
59. Kramer, L.; Turk, D.; Turk, B. The Future of Cysteine Cathepsins in Disease Management. Trends Pharmacol. Sci. 2017, 38, 873-898. [CrossRef]

60. Pečar Fonović, U.; Mitrović, A.; Knez, D.; Jakoš, T.; Pišlar, A.; Brus, B.; Doljak, B.; Stojan, J.; Žakelj, S.; Trontelj, J.; et al. Identification and characterization of the novel reversible and selective cathepsin X inhibitors. Sci. Rep. 2017, 7, 11459. [CrossRef]

61. Sadaghiani, A.M.; Verhelst, S.H.L.; Gocheva, V.; Hill, K.; Majerova, E.; Stinson, S.; Joyce, J.A.; Bogyo, M. Design, synthesis, and evaluation of in vivo potency and selectivity of epoxysuccinyl-based inhibitors of papain-family cysteine proteases. Chem. Biol. 2007, 14, 499-511. [CrossRef]

62. Hafner Pišlar, A.; Zidar, N.; Kikelj, D.; Kos, J. Cathepsin X promotes 6-hydroxydopamine-induced apoptosis of PC12 and SH-SY5Y cells. Neuropharmacology 2014, 82, 121-131. [CrossRef] [PubMed]

63. Cuddapah, V.A.; Robel, S.; Watkins, S.; Sontheimer, H. A neurocentric perspective on glioma invasion. Nat. Rev. Neurosci. 2014, 15, 455. [CrossRef] [PubMed]

64. Obermajer, N.; Jevnikar, Z.; Doljak, B.; Sadaghiani, A.M.; Bogyo, M.; Kos, J. Cathepsin X-mediated $\beta 2$ integrin activation results in nanotube outgrowth. Cell. Mol. Life Sci. 2009, 66, 1126-1134. [CrossRef] [PubMed]

65. Pečar Fonović, U.; Jevnikar, Z.; Rojnik, M.; Doljak, B.; Fonović, M.; Jamnik, P.; Kos, J. Profilin 1 as a Target for Cathepsin X Activity in Tumor Cells. PLoS ONE 2013, 8, e53918. [CrossRef]

66. Hattori, T.; Ohsawa, K.; Mizuno, Y.; Kato, K.; Kohsaka, S. Synthetic peptide corresponding to 30 amino acids of the C-terminal of neuron-specific enolase promotes survival of neocortical neurons in culture. Biochem. Biophys. Res. Commun. 1994, 202, 25-30. [CrossRef]

67. Hattori, T.; Takei, N.; Mizuno, Y.; Kato, K.; Kohsaka, S. Neurotrophic and neuroprotective effects of neuron-specific enolase on cultured neurons from embryonic rat brain. Neurosci. Res. 1995, 21, 191-198. [CrossRef]

68. Tapia, F.J.; Barbosa, A.J.A.; Marangos, P.J.; Polak, J.M.; Bloom, S.R.; Dermody, C.; Pearse, A.G.E. Neuron-specific enolase is produced by neuroendocrine tumours. Lancet 1981, 1, 808-811. [CrossRef]

69. Baebler, Š.; Svalina, M.; Petek, M.; Stare, K.; Rotter, A.; Pompe-Novak, M.; Gruden, K. quantGenius: Implementation of a decision support system for qPCR-based gene quantification. BMC Bioinform. 2017, 18, 276. [CrossRef]

70. Kassambara, A.; Mundt, F. factoextra: Extract and Visualize the Results of Multivariate Data Analyses. R Package Version 1.0.7. 2020. Available online: https:/ /CRAN.R-project.org/package=factoextra (accessed on 1 February 2022).

71. Maechler, M.; Rousseeuw, P.; Struyf, A.; Hubert, M.; Hornik, K. cluster: Cluster Analysis Basics and Extensions. R Package Version 2019.

72. Lah, T.T.; Novak, M.; Pena, A.M.A.; Marinelli, O.; Žvar, B.B.; Majc, B.; Mlinar, M.; Bošnjak, R.; Breznik, B.; Zomer, R.; et al. Cannabigerol Is a Potential Therapeutic Agent in a Novel Combined Therapy for Glioblastoma. Cells 2021, 10, 340. [CrossRef]

73. Mitrović, A.; Sosič, I.; Kos, Š.; Tratar, U.L.; Breznik, B.; Kranjc, S.; Mirković, B.; Gobec, S.; Lah, T.T.; Serša, G.; et al. Addition of 2-(ethylamino)acetonitrile group to nitroxoline results in significantly improved anti-tumor activity in vitro and in vivo. Oncotarget 2017, 8, 59136-59147. [CrossRef]

74. Breznik, B.; Motaln, H.; Vittori, M.; Rotter, A.; Lah, T.T. Mesenchymal stem cells differentially affect the invasion of distinct glioblastoma cell lines. Oncotarget 2017, 8, 25482-25499. [CrossRef]

75. Moriconi, C.; Palmieri, V.; Di Santo, R.; Tornillo, G.; Papi, M.; Pilkington, G.; De Spirito, M.; Gumbleton, M. INSIDIA: A FIJI Macro Delivering High-Throughput and High-Content Spheroid Invasion Analysis. Biotechnol. J. 2017, 10, 1700140. [CrossRef] 